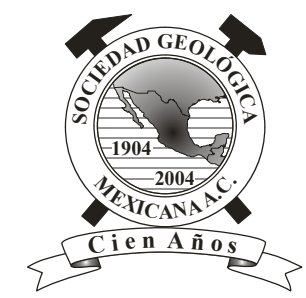

\title{
Los procesos colmatantes en dispositivos de gestión de la recarga de acuíferos y empleo de la termografía para su detección y estudio. Un ensayo metodológico en el acuífero "Los Arenales", España
}

\author{
Enrique Fernández-Escalante ${ }^{1, *}$, Ignacio Prieto-Leache ${ }^{2}$ \\ ${ }^{1}$ TRAGSA I+D+i, Julian Camarillo 6B 4 ${ }^{\circ} .28037$ Madrid. \\ ${ }^{2}$ TRAGSATEC, Julian Camarillo 6B 3․ 28037 Madrid. \\ *efernan6@tragsa.es
}

\section{Resumen}

El empleo de la termografía para fines técnicos representa una herramienta con amplitud de aplicaciones, especialmente en arquitectura, donde se utiliza desde hace años, encontrándose su uso menos contrastado en otras ciencias y ramas técnicas.

La colmatación es considerada el mayor impacto ambiental negativo que afecta a los dispositivos de "recarga artificial".

A tenor de las experiencias llevadas a cabo en el proyecto de I+D+i DINA-MAR de gestión de la recarga de acuíferos en el marco del desarrollo sostenible, en 2010 se iniciaron estudios enfocados a la detección y distribución de procesos colmatantes en dispositivos de gestión de la recarga (antes recarga artificial), tanto físicos como químicos, biológicos y sus combinaciones, mediante imágenes radiométricas y fotografías de campo.

Para ello, además del muestreo, análisis in situ y clasificación con lupa binocular, se han tomado termografías seriadas en balsas y canales en uno de los laboratorios experimentales donde se ha desarrollado el proyecto: La Cubeta de Santiuste (Segovia, España). En concreto se han estudiado localizaciones puntuales bien conocidas mediante otras metodologías, como análisis químicos, modelos de interacción, aforos secuenciales, ensayos de infiltración seriados, etcétera.

El objetivo del artículo es caracterizar los procesos colmatantes en la zona de estudio, correlacionar los resultados de las termografías con los obtenidos por otros procedimientos, cartografiar la colmatación por tipologías e intentar extrapolar las conclusiones obtenidas a otros lugares menos conocidos del mismo acuífero y/o de escenarios análogos. Así mismo, se propone una metodología para la aplicación de la termografía en hidrogeología, y en especial, en estudios de "recarga artificial". Como resultados más relevantes, cabe destacar:

- Las técnicas termográficas aplicadas a la caracterización de procesos colmatantes han arrojado resultados coincidentes, en general, con la diferenciación por otros métodos.

- La línea de acción debe continuar con tendencia a la obtención de una "paleta térmica" suficientemente precisa como para detectar las variaciones en la "firma térmica" motivadas por cambios en el sistema suelo-acuífero-agua.

- El conocimiento de la distribución de los procesos colmatantes incipientes permite mejorar diseños y planificar operaciones de limpieza y mantenimiento de forma más eficaz.

- La técnica parece ser susceptible de alcanzar importantes avances y, aunque actualmente no es determinante, complementa otras metodologías de estudio.

Palabras clave: termografía, hidrogeología, colmatación, Acuífero de los Arenales, recarga artificial, DINA-MAR.

\footnotetext{
Abstract

The use of thermography for technical purposes is a tool with a broad range of applications, especially in architecture, where it has been used for years. Nevertheless its use in other technical fields and in science has been less tested.
} 
Clogging is considered the major negative environmental impact affecting the "artificial recharge" devices.

According to the experiments carried out in the framework of the R\&D DINA-MAR Project related to management of aquifer recharge in the context of sustainable development, since 2010 studies aimed at the study of clogging in managed aquifer recharge (before artificial recharge) facilities have been carried out, specifically the detection and distribution of physical, chemical and biological clogging processes and their synergistic combinations, by means of radiometric images and field photographs.

In addition to sampling, on site analysis and classification by binocular microscope, serial radiometric images have been taken in the infiltration ponds and canals of the main field site used as an experimental laboratory where the project has been developed: Santiuste basin (Segovia, Spain). The work has been focused, specifically, to locations already studied and well known through other methods, such as chemical analysis, interaction models, sequential gauging tests, infiltration tests, etc.

The article aims to characterize the clogging processes in the study area, correlate the results of the thermograms with those obtained by other procedures, map the different clogging processes by their nature and also, try to extrapolate practical conclusions to other less known sites from the same aquifer and/or analogous scenarios. It also proposes a methodology for the application of thermography in hydrogeology, especially in "artificial recharge" studies. The following results are worth mentioning:

- Thermographic techniques applied to the characterization of clogging typologies have matched, in general, differentiation by other methods.

- The line of action must continue with a tendency to reach a "thermal palette" sufficiently precise as to detect variations in the thermal signature motivated by changes in the soil-aquifer-water system.

- Knowledge of the distribution of the incipient clogging processes allows improving designs and scheduling maintenance operations more efficiently.

- The technique seems likely to achieve significant progress and, although it is not decisive, complements other methodologies of study.

Keywords: thermography, hydrogeology, clogging, Los Arenales aquifer, artificial recharge, DINA-MAR.

\section{Introducción}

Durante los nueve años de operatividad de los dispositivos de recarga artificial de acuíferos o Managed Aquifer Recharge (en adelante MAR) construidos por el Ministerio de Medio ambiente, Rural y Marino (MARM), antiguo Ministerio de Agricultura del Gobierno de España (MAPA) y la Junta de Castilla y León (JCL) en el acuífero de los Arenales (acuífero arenoso eólico principalmente situado en Castilla y León, provincias de Segovia y Valladolid principalmente), se ha llevado a cabo un seguimiento simultáneo a la recarga artificial.

Los sectores con especial seguimiento han sido la Cubeta de Santiuste y la comarca del Carracillo (Segovia). En ellos se han estudiado las fortalezas y debilidades de la gestión de los dispositivos (canales, balsas y pozos de gran diámetro) en aras de la progresiva mejora de su efectividad, mediante la modificación de los diseños de obra que posibiliten incrementar la tasa de infiltración y los volúmenes recargados.

Los trabajos citados en este artículo se centran en el primero de ambos dispositivos, donde se han llevado a cabo la mayor parte de los ensayos del proyecto de $\mathrm{I}+\mathrm{D}+\mathrm{i}$ DINA-MAR entre 2006 y 2011.

De todos los impactos medioambientales negativos detectados, el de mayor intensidad y escala es la colmatación, proceso que disminuye drásticamente la tasa de infiltración y reduce considerablemente la vida media de los dispositivos si su gestión es inadecuada. Existen numerosos estudios sobre la colmatación, tema clásico en materia de recarga artificial. Por citar algunos, se mencionan los trabajos de Pérez-Paricio (2000) y Fernández-Escalante (2005), donde son definidos estos procesos.

En la zona de estudio donde se centra este artículo se han detectado procesos colmatantes de tipo físico, biológico, químico y sus combinaciones. A estas hay que añadir la colmatación gaseosa y la generada por compactación. El predominio de un tipo de mecanismo sobre otro depende de varios factores, entre los que cabe destacar la calidad de las aguas de recarga y su caudal, la granulometría del medio receptor, tipo de sedimentos y superficie de infiltración, aunque hay multitud de procesos adicionales implicados que hacen de la colmatación un fenómeno harto complejo.

En este sentido, la detección de procesos cuando la colmatación se manifiesta como una costra superficial o cake suele ser efectiva simplemente por inspección visual directa. El problema se complica considerablemente cuando ésta se concentra a determinadas profundidades y cuando hay colmatación química, casuísticas constatadas en esta zona de trabajo.

Las medidas aplicadas para minimizar este impacto son fundamentalmente preventivas, destacando las llevadas a cabo in itinere, como el pretratamiento mediante filtración por arena gruesa o gravilla (incluso tamices metálicos), la corrección de la calidad de las aguas de origen fluvial modificando su pH (aumentando la superficie de contacto con gravas bien silíceas o calcáreas intercaladas en el canal), y la adopción de Técnicas de Tratamiento de Suelo y Acuífero (en adelante SATs) para reducir la entrada de aire al acuífero y minimizar la colmatación (Fernández- 
Escalante, 2009). Este tipo de acciones preventivas se ven complementadas por acciones predictivas, línea en la que la termografía juega un importante papel.

Habida cuenta de que la colmatación se distribuye de manera heterogénea, queda abierta la puerta para la aplicación de nuevas tecnologías para su detección y para el estudio de la distribución de procesos superficiales. Para ello se ha iniciado una metodología relativamente "nueva" basada en la absorción de calor por la superficie del terreno y el análisis de la imagen térmica, así como su firma térmica (calor emitido desde un objeto).

Esta línea de acción, al ser una técnica pasiva, pretende complementar las ya emprendidas (en general mediante el empleo de SATs) en el proyecto de investigación DINAMAR, cuyo fin último es el diseño de dispositivos de gestión de la recarga que tengan una eficiencia elevada, todo ello en el marco de la gestión hídrica para el regadío.

\section{Objetivos}

Los principales objetivos son el estudio de las tipologías de procesos colmatantes presentes en los dispositivos de gestión de la recarga en un sector específico del acuífero de los Arenales, así como su caracterización.

La zona de estudio elegida ha sido la Cubeta de Santiuste, donde se lleva a cabo un seguimiento controlado de los ciclos de recarga artificial desde su origen, en 2002, y se pretende alcanzar una caracterización de la distribución de la colmatación conforme al tipo de procesos predominantes en cada sector, mediante inspección visual, muestreo, observación con lupa binocular y microscopio, junto con análisis químicos de aguas y suelos.

En este contexto se está ensayando el empleo de termógrafos como tecnología novedosa para estudiar la distribución de la colmatación en el espacio (balsas y canales de gestión de la recarga) y en el tiempo (períodos con mayor intensidad de este impacto ambiental). De este modo se va a determinar la distribución espacial de los procesos colmatantes, caracterizando y sectorizando los más abundantes y generando una cartografía específica para tal fin. Esta línea de acción pretende estudiar, además, qué parámetros influyen en la distribución de estos procesos, tales como la microtopografía, la heterogeneidad y anisotropía de los acuíferos, química del suelo y del agua, temperatura del agua, perfil más idóneo de los dispositivos (calado, perímetro mojado e inclinación de los taludes, etcétera). Este artículo se centrará en la diferenciaciónmediante inspección visual y microscopía.

Además de su detección por termografía, análisis de cada patrón térmico e interpretación de las firmas térmicas, se pretende contrastar los resultados obtenidos con otros procedimientos, especialmente con ensayos de infiltración llevados a cabo en zonas concretas, iniciando la definición de paletas térmicas (esquemas de color que permiten detectar las variaciones en los patrones térmicos en el futuro) para el estudio de tendencias evolutivas.

El fin último es, por tanto, contar con una línea de acción adicional no invasiva para el análisis de la efectividad de los dispositivos de recarga empleados en este sector del acuífero, procurando mejorar su efectividad, reformulando parámetros de diseño, diseñando mejoras estructurales, implementando técnicas SAT optimizadas, y adoptando medidas que garanticen las labores de limpieza de tipo mecánico adecuadas y al menor coste posible; y por otro lado, conseguir un mantenimiento predictivo además de preventivo.

A lo largo del artículo se presentarán las actuaciones concretas para balsas y para canales de manera disociada.

\section{Estado de la cuestión}

\subsection{La termografía por infrarrojos}

La termografía por infrarrojos es una parte de la ciencia que estudia el uso de dispositivos óptico-electrónicos para detectar y medir la radiación de las superficies bajo estudio, obteniendo así su temperatura (Fluke, 2009).

Inicialmente aplicado con fines militares (Guerra de Corea 1950), hoy se aplica en varios campos de la ciencia y técnica, aunque su empleo es relativamente novedoso (De los Santos y Sánchez-Cabezas, 2011).

El término termografía se debe a Robert Hunt, quien bautizó con este nombre en 1840 un procedimiento fotográfico que procuraba copias directamente en positivo, con base en la utilización de una fuente de calor muy intensa y constante, e incluso calor en el momento del revelado de las placas. (Hillson, 1982).

Esta tecnología se ha aplicado en distintas ramas de la ciencia y la técnica desde el Siglo XIX.

En el ámbito forestal, Hunt et al., (1989) y Pierce et al., (1990) realizaron un estudio sobre el estado hídrico de las plantas en el que concluyeron que, para distintas especies forestales, los índices calculados a partir de reflectancias NIR (región espectral del infrarrojo cercano) no pueden usarse en la estimación remota de su estado hídrico. Por su parte, el departamento de Bioclimatología del INRA determinó microclimas forestales a partir de termografías del satélite americano HCMM (Heat Capacity Mapping Mission, lanzado por la NASA) aplicado al NE del Macizo Central en el marco del plan climático creado por el STEFCE (Servicio Técnico de Estudio de los Factores Climáticos del Entorno) (Lagouarde, 1983).

Las aplicaciones en el ámbito de la construcción son variadas: detección de patologías, fugas, comportamiento térmico y aislamiento, estructuras, localización de instalaciones, etcétera. Destacan los estudios de Pettersson y Axen (1980), quienes analizaron el aislamiento y comportamiento térmico de las edificaciones por medio de la termografía.

Por su parte, Gayo Moncó (2002), en su tesis doctoral, 
analiza el impacto de la humedad en edificios por medio de imágenes radiométricas.

En el campo de la medicina la aplicación es histórica y ampliamente extensa. Cabe citar, por resultar emblemática, la publicación Medical thermography, de Atsumi (1973). Se trata de una técnica aplicable en multitud de ámbitos y patologías, con abundantes ejemplos en la literatura científica.

\subsection{Aplicaciones de la termografía por infrarrojos a la} hidrogeología

La aplicación de la termografía en la hidrogeología permite conocer el comportamiento térmico de los materiales geológicos en igualdad de condiciones climatológicas, facilitando un criterio de diferenciación por simple inspección visual.

Generalmente el color es un factor determinante de la absorción de calor y su irradiación por parte de los materiales, pero no exclusivo. Hay varios factores ambientales con influencia en el patrón térmico del litosoma a estudiar, tales como la radiación solar, humedad, dirección y velocidad del viento, etcétera (DINA-MAR, 2010).

Aunque no se han encontrado publicaciones específicas sobre esta temática, cabe destacar trabajos relacionados en materia de hidrogeología o afines. Tal es el caso de los realizados por Lawrence and Golden (1980), quienes estudiaron el efecto "isla de calor" en ciudades de California y Arizona (USA), así como el balance energético y las formas de evolución del calor mediante infrarrojos. Este estudio se centra en la respuesta termográfica de distintos materiales del entorno urbano y sus variaciones con las condiciones climatológicas. Concluyen elaborando un modelo de la evaluación del calor en grandes ciudades con el tiempo.

Más recientemente, Edmond et al., (2009) estudiaron la concentración de hielo sólido en aguas de ríos de Quebec y Montreal (Canadá) en distintos períodos, cuantificando la concentración de hielo y su distribución. Concluyeron en la importancia de la termografía como técnica más idónea para estudios geoespaciales, por delante de la teledetección, el radar o fotografías aéreas.

Por otro lado, Shahraeeni y Or (2010) estudiaron la firma térmica de superficies con evaporación constatada, su distribución en el espacio y su variación en el tiempo. El ensayo fue ampliado a la tercera dimensión mediante columnas de arena, postulando algoritmos y soluciones analíticas para el flujo evaporativo.

3.3. La colmatación. Estado del arte y tipologías detectadas en los dispositivos de recarga gestionada del Acuífero de Los Arenales.

El estudio de la colmatación constituye un tema ampliamente tratado por la hidrogeología desde hace décadas, motivo por el que este artículo se ha centrado exclusivamente en los procesos detectados en la zona de estudio. La pretensión es que sean descritos de forma resumida pero actualizada, conforme a los avances tecnológicos actuales, y estudiar su presencia y distribución en el área. El apartado resume y complementa los estudios sobre colmatación presentados por Fernández-Escalante (2005) y Fernández-Escalante y García-Merino (2009).

Los suelos de la zona de estudio son, en general, arenosos. Por tanto, presentan mala estructuración, buena aireación, permeabilidad muy alta y baja retención de agua. Desde el punto de vista químico son muy pobres, con escasez de propiedades coloidales y nutrientes.

Aparecen también suelos con predominio de fracción arcillosa y niveles arcillosos lenticulares bien diferenciados en la vertical. Por definición están bien estructurados, muy mal aireados, son impermeables y retienen más agua. Desde el punto de vista químico presentan una actividad muy superior, con alta capacidad de adsorción de iones y moléculas, floculan y se dispersan (migran), son muy ricos en nutrientes, etcétera.

Los suelos limosos tienen mala estructuración, reducidas propiedades coloidales, son impermeables y con mala aireación.

La colmatación es el fenómeno de obstrucción del suelo por efecto de la recarga artificial que constituye el principal impacto negativo que afecta a este tipo de cuerpos. Afecta a la zona de estudio de manera diferencial, tanto en las tipologías presentes como en su grado de desarrollo.

Es preciso que los procesos colmatantes tengan una caracterización inicial para poder realizar un adecuado seguimiento de su evolución y diseñar actuaciones paliativas.

Genéricamente, la velocidad de penetración del agua infiltrada en un suelo depende de la textura, la estructura y la heterogeneidad del suelo, pero también de su humedad $\mathrm{y}$ de la profundidad del nivel freático. Algunos de los factores que también afectan la capacidad de infiltración del suelo son su compactación, lavado de partículas finas en los poros superficiales y macroporos (grietas y fisuras); a estos hay que añadir la vegetación y el tipo de cultivo. De manera menos genérica, pero bien constatada como se verá a continuación, influye la cantidad de aire entrampado en el acuífero, que penetra en el mismo desde la atmósfera directamente o transportado por el agua (de lluvia o de recarga artificial) en disolución o suspensión.

Se han detectado procesos colmatantes tanto en fondo como en las paredes de los dispositivos. Las tipologías más abundantes de los procesos son de tipo físico, biológico, químico (en general motivados por la precipitación de calcita bajo balsas y canales [en Fernández-Escalante et al., 2009]) y sus combinaciones (Figuras 4a a h). La coexistencia de distintas tipologías trae consigo procesos sinérgicos. A estas hay que añadir, aunque no se trate de procesos colmatantes puros, la colmatación gaseosa y la generada por compactación, en tanto disminuyen la tasa de infiltración del fondo de las balsas y canales, e incluso, 
aunque en menor cuantía, en las paredes.

En cuanto a la colmatación física, cabe destacar la presencia de una costra o cake en gran parte de las balsas y canales. Este cubrimiento de arcillas y limos se origina en superficie, bien por efecto de la retención de partículas en suspensión (finos), que quedan bloqueadas en el acuífero y que sufren una compresión posterior; o por efecto self mulching.

En el perfil del suelo las partículas más gruesas se depositan en la superficie del suelo o a poca profundidad, mientras que las más finas son más penetrativas y pueden quedar "atrapadas" en los poros, rellenándolos y dificultando así el flujo del agua. Una vez que el movimiento de las partículas más grandes se ha bloqueado, las propias partículas sirven como filtro para atrapar partículas sucesivamente más pequeñas, hasta que el suelo se colmata. Consecuentemente, la conductividad hidráulica se reduce a una fracción respecto a su valor original.

El efecto self mulching se manifiesta como una costra superficial como consecuencia del distinto grado de humedecimiento del suelo en función de la profundidad (Ryan y Elimelech, 1996). Su espesor es mayor en las concavidades de las ondulaciones del fondo de las balsas y en la zona más profunda del perfil de los canales (Figura 1a).

A estos fenómenos hay que añadir los procesos de eluviación-iluviación de arcilla, proceso muy complejo producido por la movilización de las arcillas procedentes del agua de recarga (de lluvia y artificial). Desde los horizontes superficiales, las partículas más finas pasan a la solución del suelo en suspensión. Al infiltrarse por los poros de mayor tamaño, forman delgadas películas, primero acuosas, luego de arcilla dispuestas paralelamente entre sí, formando cutanes o arcilanes o clay-skins. Estas rodean las paredes de los macroporos quedando fuertemente retenidas (Figura 2 y Figura $5 \mathrm{~b}$ y c) y rodeadas de geles silicatados, ácidos húmicos y otras sustancias coloidales que complican el proceso. Con las siguientes lluvias o ciclos de recarga, el proceso se repite, incidiendo en la capacidad de recarga del dispositivo.

En general se aprecia un nivel de cake y horizontes de iluviación en el sector sur del dispositivo, hasta aproximadamente $20 \mathrm{~cm}$ de profundidad como promedio (Figura 1b), según se estudia en el apartado 6.2.

Los procesos colmatantes químicos suelen ser de dos tipos. Por un lado se ha detectado calcita, bien en costras carbonatadas superficiales (Figura $4 \mathrm{c} \mathrm{y} \mathrm{d}$ ) o en forma de precipitados calcáreos en una franja localizada entre 40 y $60 \mathrm{~cm}$ de profundidad bajo el fondo de los dispositivos (detectada gracias a las curvas de los ensayos de infiltración (DINA-MAR, 2010). Las primeras están generadas por la precipitación de minerales presentes en el agua de recarga al disminuir la concentración del $\mathrm{CO}_{2}$ disuelto, proceso motivado con frecuencia por la actividad fotosintética de las aguas. En el segundo caso, su origen es atribuido a cambios de temperatura de las aguas de recarga a medida que se infiltran en el acuífero, especialmente por su calentamiento

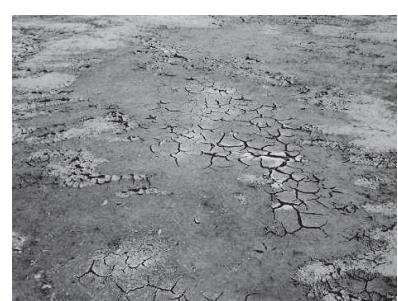

a)

Figuras 1 a) y b). Formación de cake en el fondo de la balsa de decantación por efecto self-mulching con distribución en depresiones conforme a la microtopografía. Fotografía tomada por los autores.
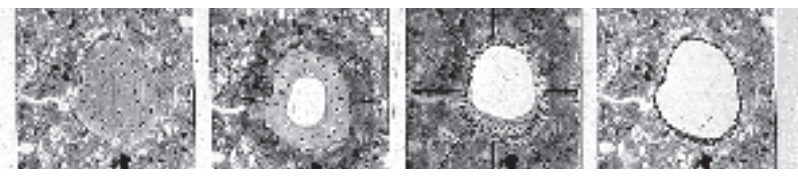

Figura 2. Evolución de la formación de los clay-skins o cutanes de arcilla (Tomado de http://edafologia.ugr.es/introeda/).

bajo condiciones superficiales muy frías (ciclos de helada).

La otra tipología detectada corresponde a procesos sulfurados de tonalidad oscura asociados a ambientes reductores, relacionados con abundancia de pirita diagenética.

Los procesos colmatantes biológicos se manifiestan principalmente por el incremento de materia orgánica en el suelo, en general procedente de las aguas de recarga y especialmente del vertido de la depuradora (Figura 4f). La carga biológica y el carbono orgánico modifican las propiedades físicas y químicas, confieren al suelo un color oscuro, que varía según el grado de humificación y el porcentaje de ésta en el perfil del suelo, al tiempo que facilitan la génesis de agregados, cuya capacidad para retener el agua facilita el asentamiento de vegetación.

Los procesos colmatantes bioquímicos se manifiestan en sectores con abundancia de algas, en general azules filamentosas. Estas catalizan la precipitación de minerales al extraer $\mathrm{CO}_{2}$ disuelto en su actividad fotosintética (Figura 4e). Se han detectado además bacterias, en especial colonias del tipo Pseudomona, coloides, diatomeas, semillas, pólenes y partículas en suspensión no determinadas, algunas con apariencia de gel (Figura 5).

De este modo, la zona de estudio presenta una amplia variedad de procesos colmatantes, gran parte en coexistencia (Figura 4g y 4h), al interaccionar la totalidad de los vectores con mayor influencia en la colmatación definidos por Van Beek (1986). La Figura 3 muestra un diagrama de rueda que relaciona las interacciones principales de los distintos procesos y vectores identificados. Cada "radio" está escalado dentro de los intervalos de magnitud (límite inferior en el eje de la rueda y superior en el extremo) medidos en la naturaleza.

Aunque hay sectores con presencia de la mayor parte de los procesos detectados (Figura $4 \mathrm{~g} \mathrm{y} \mathrm{h}$ ), en general 


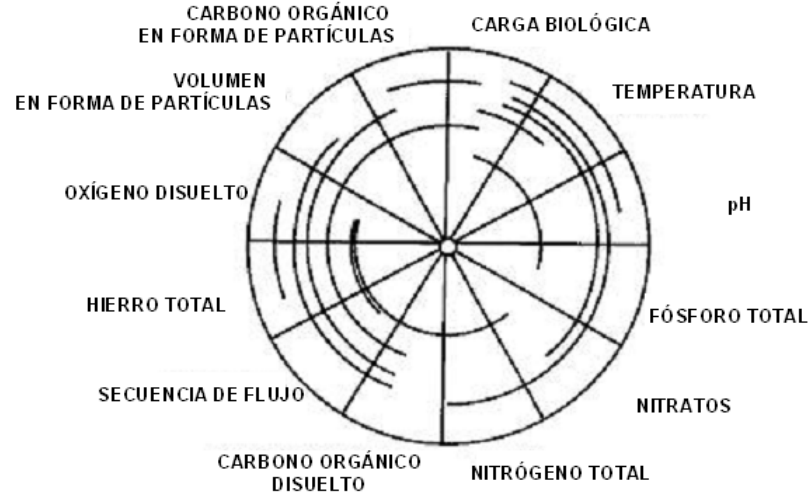

Figura 3. Factores que afectan el crecimiento de microorganismos y taponamiento del pozo de recarga (modificado de Van Beek, 1986). y conforme a sus propiedades, se aprecia un tipo de colmatación predominante en cada sector. De este modo se ha llevado a cabo una primera sectorización (Apartado 6.2).

\section{Materiales y métodos}

La distribución de la colmatación en los distintos sectores se ha llevado a cabo por inspección visual directa, muestreo y observación con lupa binocular y microscopio. Los resultados han sido contrastados con los patrones térmicos obtenidos en cada estación, definiendo firmas y paletas térmicas, como complemento de la caracterización inicial.

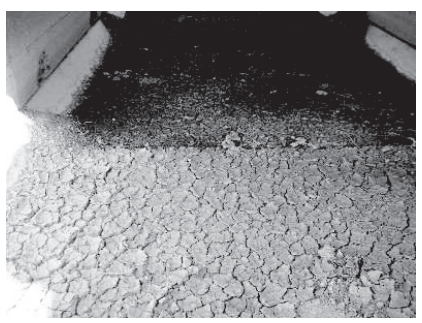

a)

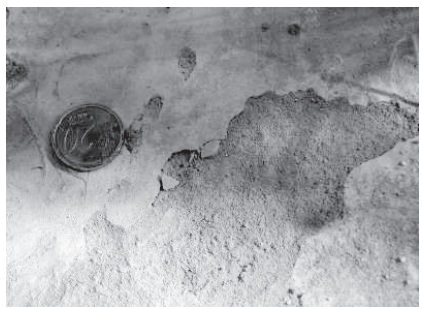

d)

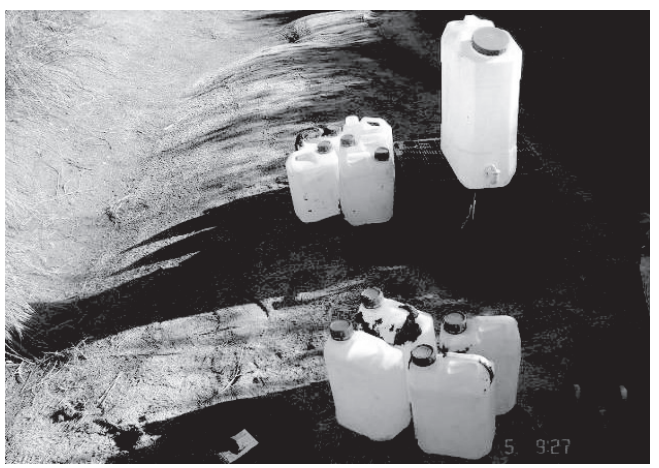

g)

b)

e)
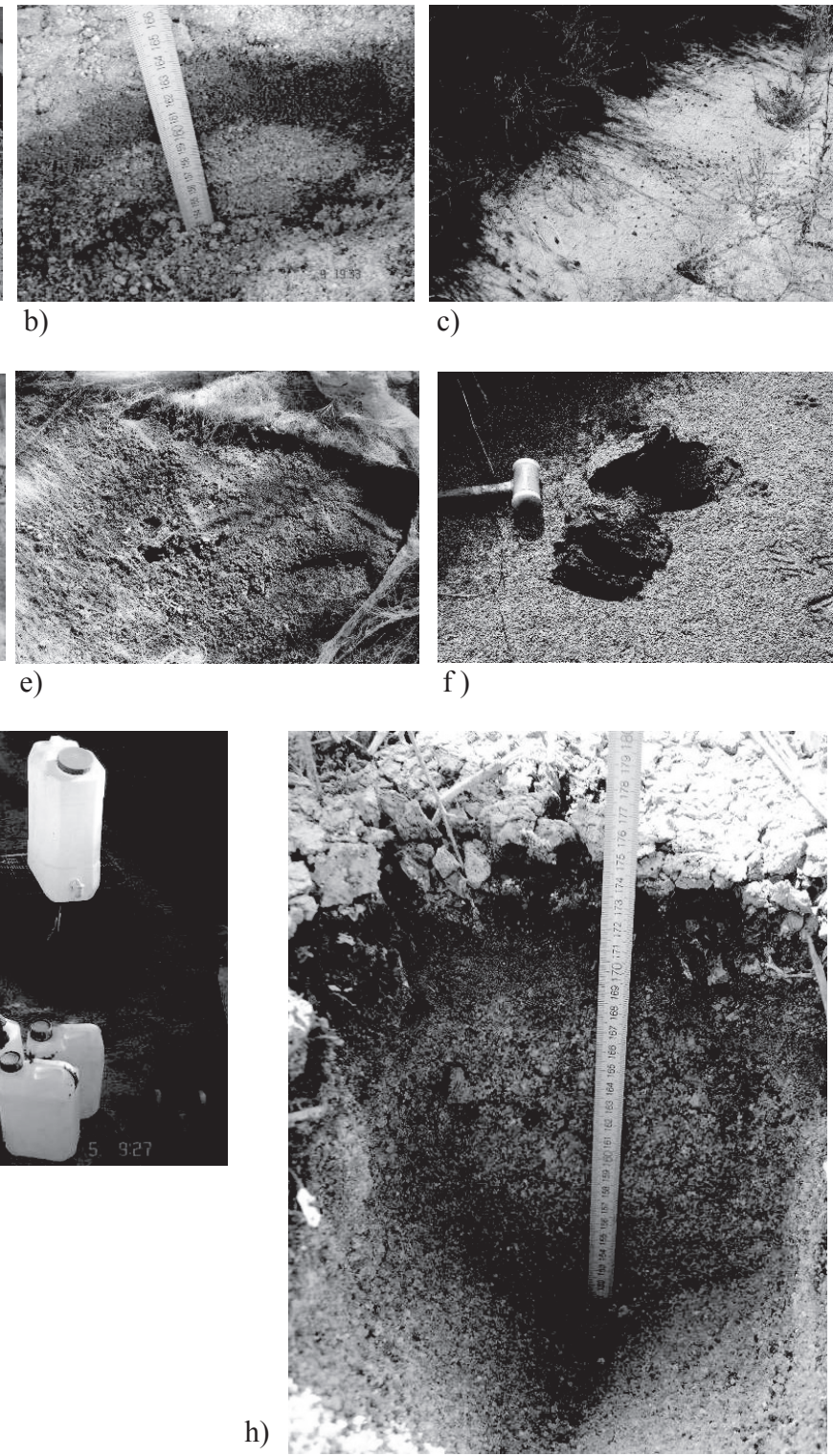

Figuras 4 a) a h) (respectivamente desde el extremo superior izquierdo al inferior derecho). Ejemplos de los procesos colmatantes detectados en balsas y canales de "recarga artificial". Predominio de procesos físicos (a y b), químicos (c y d), biológicos (e y f) y combinaciones (g y h), tales como procesos físicos y químicos asociados a algas filamentosas. Fotos a distintas escalas. 


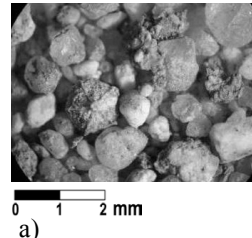

b)
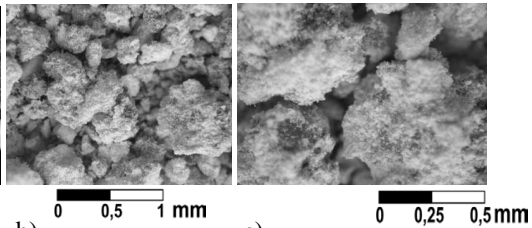

c)

Figuras 5 a) a c). Fotografías con lupa binocular del medio receptor y sus procesos colmatantes a) finos, agregados de bioclogging, esporas, granos de polen, cutanes, etc., b y c) cutanes y película arcillosa recubriendo los granos de arena. Escala gráfica $(\mathrm{mm})$. Factor de magnificación 200, 400 y $800 x$ respectivamente.

Los procesos colmatantes han sido discretizados mediante la observación visual directa, muestreo y tratamiento con ácido clorhídrico y observación con lupa binocular Olympus SZ (Figura 6b) adaptada a cámara digital C-8080.

En cuanto a la toma de datos complementarios, tales como la determinación de permeabilidades y tasas de infiltración in situ, se han empleado técnicas "convencionales", en general infiltrómetros de doble anillo (hincando los anillos entre tres y cinco $\mathrm{cm}$ bajo la superficie del suelo) (Figura 6a).

De forma adicional se han realizado granulometrías y análisis químicos de aguas y suelos, incluyendo la toma de parámetros inestables. Tanto el muestreo como la parte analítica se han llevado a cabo conforme a la normativa UNE-EN 25667 (AENOR, 1995).

El estudio de la Zona No Saturada (ZNS) se lleva a cabo mediante los sensores integrados en las estaciones de telecontrol llamadas "DINA-MAR ZNS". Constan de humidímetros, termómetros y tensiómetros conectados a data-loggers. Registran en continuo 5 parámetros en las inmediaciones de un canal. Con ellos e indirectamente se puede estimar el aire retenido en los poros del suelo. Detalles de las estaciones se encuentran en Fernández-Escalante y García-Merino (2009).

Los análisis químicos de las probetas de muestras de colmatación han sido postergados para futuras líneas de financiación y quedan fuera de las pretensiones de este artículo.

La toma de termografías se ha llevado a cabo mediante una cámara termográfica modelo Therma-Cam E2 de ThermaCAM ${ }^{\mathrm{TM}}$ (Flir Systems) (Figura 9a).

Metodológicamente, se trata de una línea de acción iniciada en mayo de 2010 que permite detectar, mediante la distribución de la temperatura en las balsas, canales y perfiles realizados en su fondo, zonas preferenciales de generación de colmatación.

El fundamento teórico principal se basa en las siguientes premisas: en general, las arenas colmatadas por sedimentos, especialmente finos, suelen tener una coloración más oscura y, habitualmente, una mayor absorción de calor (aunque otros materiales de tonalidades más claras tienen una capacidad térmica superior). Del mismo modo, la

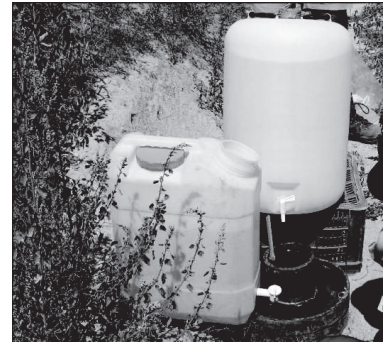

a)

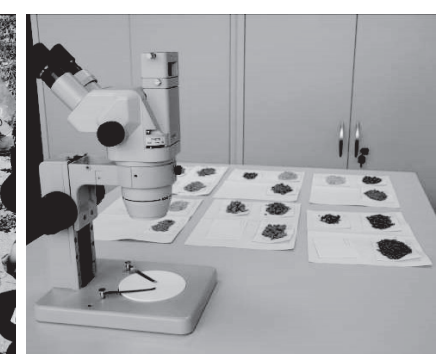

b)
Figura 6 a) y b). Infiltrómetro de doble anillo durante un ensayo y lupa binocular.

precipitación puntual de niveles calcáreos y encostramientos en las paredes y fondo de las balsas de infiltración y canales absorben (e irradian) de manera diferente el calor respecto al terreno natural de sus inmediaciones. Los procesos de bioclogging presentan variedades amplias en su coloración. Estos cambios en el espectro cromático, con frecuencia, pueden resultar imperceptibles para el ojo humano, si bien su capacidad térmica es diferente y su manifestación termográfica (o firma térmica) también. Bajo esta óptica se han llevado a cabo campañas de campo para la toma de termogramas y su correlación con la colmatación identificada mediante otras tecnologías.

Se han tomado imágenes radiométricas en las zonas donde se llevan a cabo ensayos de infiltración periódicos, analizando detenidamente la distribución de la colmatación por la diferente irradiación de calor y consecuente diferente temperatura (distinto patrón térmico) que adquieren las zonas más colmatadas con respecto a las zonas sin colmatar. Este hecho se manifiesta con distintas coloraciones según la capacidad térmica de cada objeto (firma térmica), aunque hay numerosos factores "contaminantes" que enmascaran los resultados, adquiriendo vital importancia las interpretaciones cuidadosas de las firmas térmicas ante el riesgo de cometer imprecisiones.

En general las arenas eólicas son más claras que los procesos colmatantes, con fuerte carga de finos $\mathrm{y}$, en general, tonalidad más oscura. Estos contrastes aportan una línea de acción al estudio de la distribución de la colmatación, si bien es preciso disociar qué procesos orgánicos y físicos tienen una mayor influencia en la absorción de calor.

En la Figura 7 se han montado pares fotografíatermografía a modo de ejemplo. El primero de ellos corresponde a la zona de vertido de la depuradora por lagunaje de Santiuste al canal de recarga artificial (Este), cuya posición se puede consultar en la Figura 18. A pesar de que el agua se comporta como un reflector especular, la superficie rugosa permite diferenciar un patrón térmico por cambios en la emisividad. La imagen radiométrica aporta información relativa al proceso de mezcla del vertido al canal. Además ambas aguas presentan temperaturas diferentes y el termógrafo aporta una firma térmica que permite apreciar el proceso de mezcla, la creación de 
a)

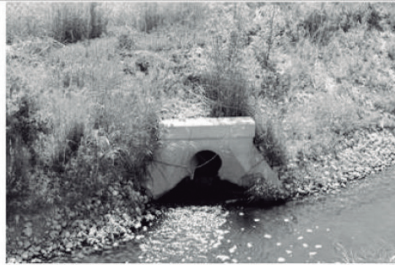

b)
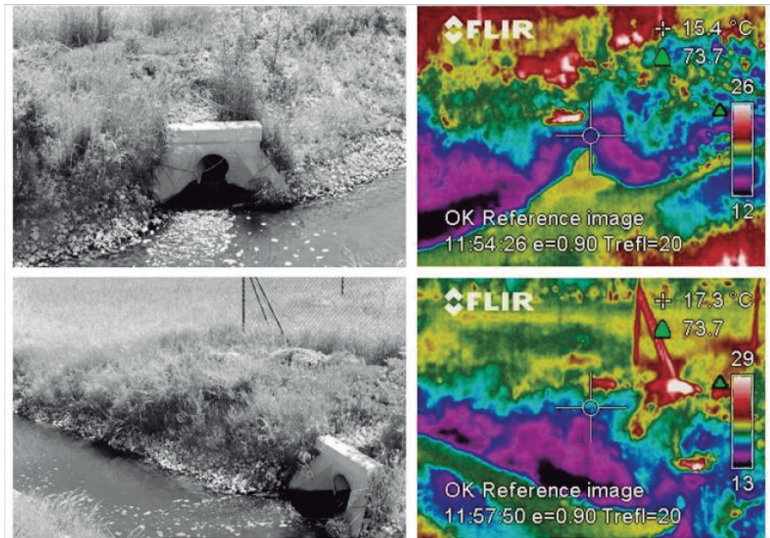

Figura 7 a) y b). Comparación entre los aspectos de fotografías y termografías en la zona de mezcla del vertido desde la depuradora por lagunaje de Santiuste de San Juan Bautista al canal de recarga artificial (Figura tomada de DINA-MAR, 2010).

contornos isotérmicos, islas de calor y de frío, etcétera. Este patrón térmico, además, permite estimaciones de la velocidad de flujo de las aguas.

La Figura 8 corresponde a una canalización en Guadalix (Madrid) cubierta por materiales de diferente granulometría y grado de compactación. A tenor de su observación, se aprecia la diferente absorción de calor en función del sustrato, tamaño de los clastos y grado de compactación en la zahorra, en función del perfil de observación (perspectiva), etcétera.

Aunque esta técnica no está tan desarrollada como para hacer mediciones cuantitativas, presenta una gran validez en cualitativas y en aproximaciones cuánticas, abriendo una interesante línea de acción en permanente mejora. Se están realizando, además, termografías en distintos momentos del día, determinando la mejor hora para su detección, en distintos períodos del año, con diferentes condiciones de luz (soleado, nublado, etcétera), y con la esperanza de alcanzar en un futuro conclusiones más precisas.

La toma de termografías ha estado acompañada de medidas de humedad y temperatura superficial in situ mediante un humidímetro-termómetro Neurtek Instruments (Figura 9b), lo que ha permitido verificar resultados mediante comparativas.

Los estudios de colmatación y termografía se han centrado, especialmente, en la cabecera del dispositivo (extremo Sur), estaciones 1 y 2 (posicionadas en el mapa de la Figura 18), si bien se han hecho ensayos a lo largo de ambos canales.

\section{Descripción del área de trabajo}

El acuífero de Los Arenales o Unidad hidrogeológica 0217 tiene una extensión de $1504 \mathrm{~km}^{2}$ localizada íntegramente en la Comunidad autónoma de Castilla y León, España.

La explotación del acuífero cuaternario superficial ha

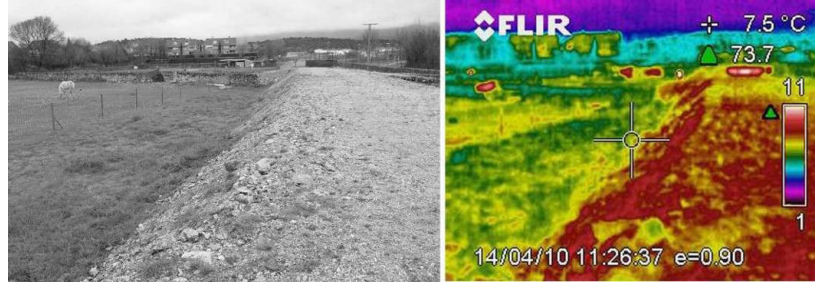

Figura 8. Par fotografía-termografía de nuevas canalizaciones cubiertas por zahorra y elementos adicionales como ejemplo del comportamiento opticoelectrónico de diversos materiales según las condiciones ambientales. Tomada por los autores.

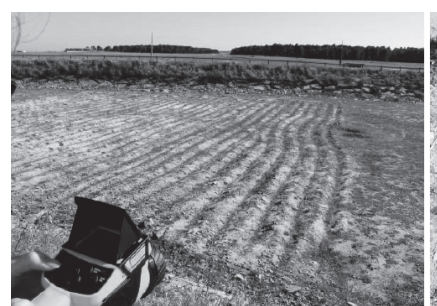

a)

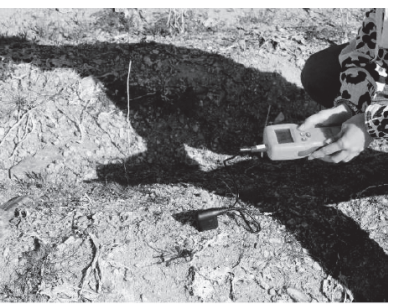

b)
Figuras 9 a) y b). Cámara termográfica Therma-Cam E2 y determinación directa de la temperatura y humedad en superficie para validar la firma térmica. Fotografías tomadas por los autores

sido creciente en las últimas décadas, motivando el descenso del nivel freático una media de $10 \mathrm{~m}$, con procesos de salinización y contaminación aparejados. Para solventar este impacto se construyeron con carácter experimental tres dispositivos de gestión de la recarga de acuíferos para regadío, localizados en la figura 10 .

La Cubeta de Santiuste es un acuífero bien conocido estatalmente gracias a las actuaciones llevadas a cabo por el Ministerio de Medio Ambiente, Rural y Marino de España, y a las actividades de $\mathrm{I}+\mathrm{D}+\mathrm{i}$ aplicadas en el mismo. Se encuentra en el sector oeste de la provincia de Segovia y sureste de Valladolid. Ubicada en la margen izquierda de los ríos Voltoya y Eresma, cuenta con una superficie de unos $50 \mathrm{~km}^{2}$ y unas 650 ha de regadío. La actividad de recarga artificial empezó en 2002/03, con un canal único con balsas intercaladas, que ha sido ampliado sucesivamente hasta la actualidad. El volumen infiltrado al acuífero ha oscilado entre 0.97 (ciclo 2004/05) y $12.19 \mathrm{hm}^{3}$ (2006/07) (Figura 13). El dispositivo cuenta con 9 años de operatividad y consta en la actualidad de $27 \mathrm{~km}$ de canal de infiltración, 5 balsas de infiltración, 3 pozos para MAR, un sistema tipo River Bank Filtration (RBF) y tres humedales artificiales. El agua siempre circula por gravedad, en ningún caso hay bombeo.

Se trata de un acuífero poligénico, predominando la facies Arévalo, constituida por arenas de un sistema dunar Cuatenario de espesor variable (hasta $50 \mathrm{~m}$ ) que rellenan una cavidad compleja de un sustrato arcilloso de edad Cenozóico (Facies Cuesta) o areno-arcilloso y yesífero (Facies Puente Runel). Esta unidad da origen a la superficie morfológica de 


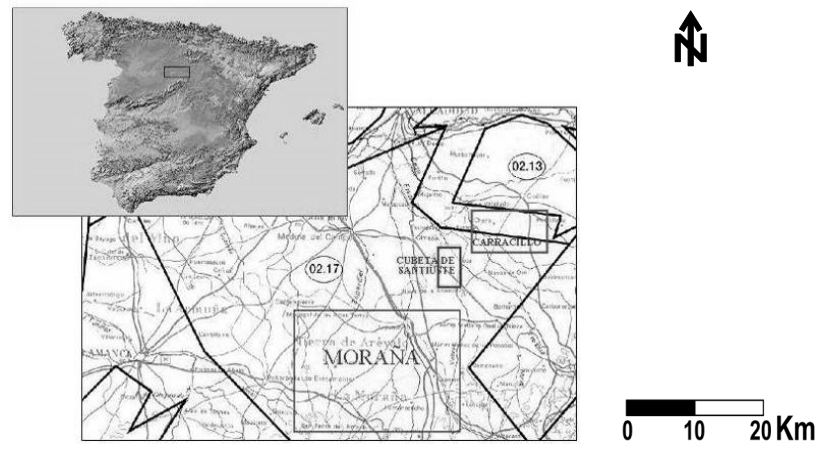

Figura 10. Posición geográfica del acuífero de Los Arenales, también llamado Unidad Hidrogeológica 02-17. Ubicación dentro de España (sin escala) y cartografía con la ubicación de los sectores Moraña, Santiuste y Carracillo (escala 1:200000). Mapas orientados al Norte.

Coca-Arévalo, constituida por depósitos arenosos de origen fluvial, parcialmente recubierta por depósitos eólicos y áreas endorréicas, con varios sistemas lagunares ya fosilizados. La descripción detallada de las facies de los acuíferos y su funcionamiento hidrogeológico se describe con detalle en MAPA, 2005 y Fernández-Escalante, 2005.

El dispositivo de recarga gestionada está compuesto por canales, balsas y pozos, que se encargan de infiltrar los excedentes invernales derivados del río Voltoya, para luego regar en el periodo estival. Comienza a partir de un pequeño embalse en el río Voltoya, desde el que parte una tubería enterrada de $10 \mathrm{~km}$ de longitud pendiente abajo, que termina en un depósito (cabecera del dispositivo) de $36 \mathrm{~m}^{3}$ dotado de caudalímetro. A continuación, aparece una balsa de decantación de $14322 \mathrm{~m}^{2}$ de superficie, de la que parten los dos canales principales (Figuras 12). El originario, "Canal Viejo" o "Este", comenzó a funcionar en 2002; y el "Canal Nuevo" u "Oeste", operativo desde 2005, discurre semiparalelo al anterior.

El "Canal Viejo" (Este) tiene un trazado que salva 30 $\mathrm{m}$ de desnivel, con una pendiente media de $0.28 \%$ a través de $10667 \mathrm{~m}$. El canal tiene 54 dispositivos de parada para incrementar la infiltración a través de una superficie que ronda los $33300 \mathrm{~m}^{2}$ (fondo y paredes).

El Nuevo Canal (Oeste) tiene una longitud total de 17293 m. Está ubicado en el sector de máximos espesores del acuífero.

El caudal procedente del río Voltoya ronda los $0.5 \mathrm{~m}^{3} / \mathrm{s}$, con un periodo de concesión otorgado por la confederación hidrográfica del Duero (CHD) desde el primero de noviembre al último día de abril. Esta concesión depende del carácter del año hidrológico.

De acuerdo con datos bibliográficos obtenidos mediante ensayos de infiltración en canales y balsas, la tasa de infiltración o permeabilidad media a lo largo del ciclo de recarga oscila entre 0.86 y $3 \mathrm{~m} /$ día; $\mathrm{K}_{\mathrm{v}}$ se estimaba en 3 m/día (IRYDA, 1990; MAPA, 1999). Según otras fuentes oscila entre 6 y 10 m/día (MOPTMA, 1994). Revisiones posteriores indican que estos datos están sobredimensionados, proponiendo para el sector Sur unos valores de permeabilidad media de $4.4 \mathrm{~m} /$ día para la $\mathrm{K}_{\mathrm{h}}$ y $0.32 \mathrm{~m} /$ día para la $\mathrm{K}_{\mathrm{v}}$ (Fernández-Escalante y GarcíaMerino, 2009).

En la Figura 11 se muestra la geología del acuífero sobrepuesta a un bloque diagrama que permite relacionar geología y orografía.

La Figura 18 presenta el trazado del dispositivo sobre la cartografía de isopacas del acuífero arenoso cuaternario y la posición de los elementos singulares, canales, balsas, estaciones de toma de datos, etcétera.

La historia de la gestión de la recarga en este dispositivo se ha llevado a cabo en estrecha colaboración con sus gestores, la comunidad de regantes de Santiuste. Su seguimiento se lleva a cabo mediante mediciones de una red de control de la piezometría (RCP) y cálculos del nivel de llenado del acuífero.

La Tabla 1 sintetiza los principales cálculos llevados a cabo por el MAPA y por el proyecto de I+D+i DINA-MAR en ocho ciclos de seguimiento de la recarga gestionada. La tabla resume, respectivamente, el año hidrológico (ciclo de recarga), la precipitación total durante el período efectivo de recarga en el área (datos de www. Inforiego.es), las fechas de inicio y final de dicha concesión, los días de operatividad total (excluyendo incidencias), el volumen total derivado del río Voltoya ( $\mathrm{Q}$ deriv), el caudal medio circulante a lo largo del canal (caudal/longitud), columna Qm canal, el volumen infiltrado en el acuífero deducido por la fluctuación del nivel del agua (método WTF modificado, en Fernández-Escalante, 2005), el porcentaje con respecto al caudal derivado (ratio) y, por último, la oscilación media (ascenso) del nivel freático medio del acuífero como consecuencia de cada ciclo de recarga artificial con respecto al nivel de llenado inicial.

\section{Análisis e interpretación de resultados}

Dado el carácter de este artículo, con una componente técnica alta, se ha optado por abordar conjuntamente la presentación de resultados y su discusión, debido a la necesidad de contar con el apoyo gráfico de las termografías en ambos apartados.

6.1. Estudios de distribución de los procesos colmatantes apoyados en pares termografía-fotografía

Las imágenes radiométricas obtenidas en las distintas campañas de campo indican grandes diferencias de temperatura en superficie, lo que proporciona un criterio para el estudio de los procesos colmatantes adicional a las vías clásicas de estudio.

En este apartado se confrontan varios pares fotografíatermografía para, con el apoyo de las técnicas restantes presentadas, estudiar la idoneidad de aplicar la termografía en la detección de la colmatación, sus posibilidades y limitaciones. 


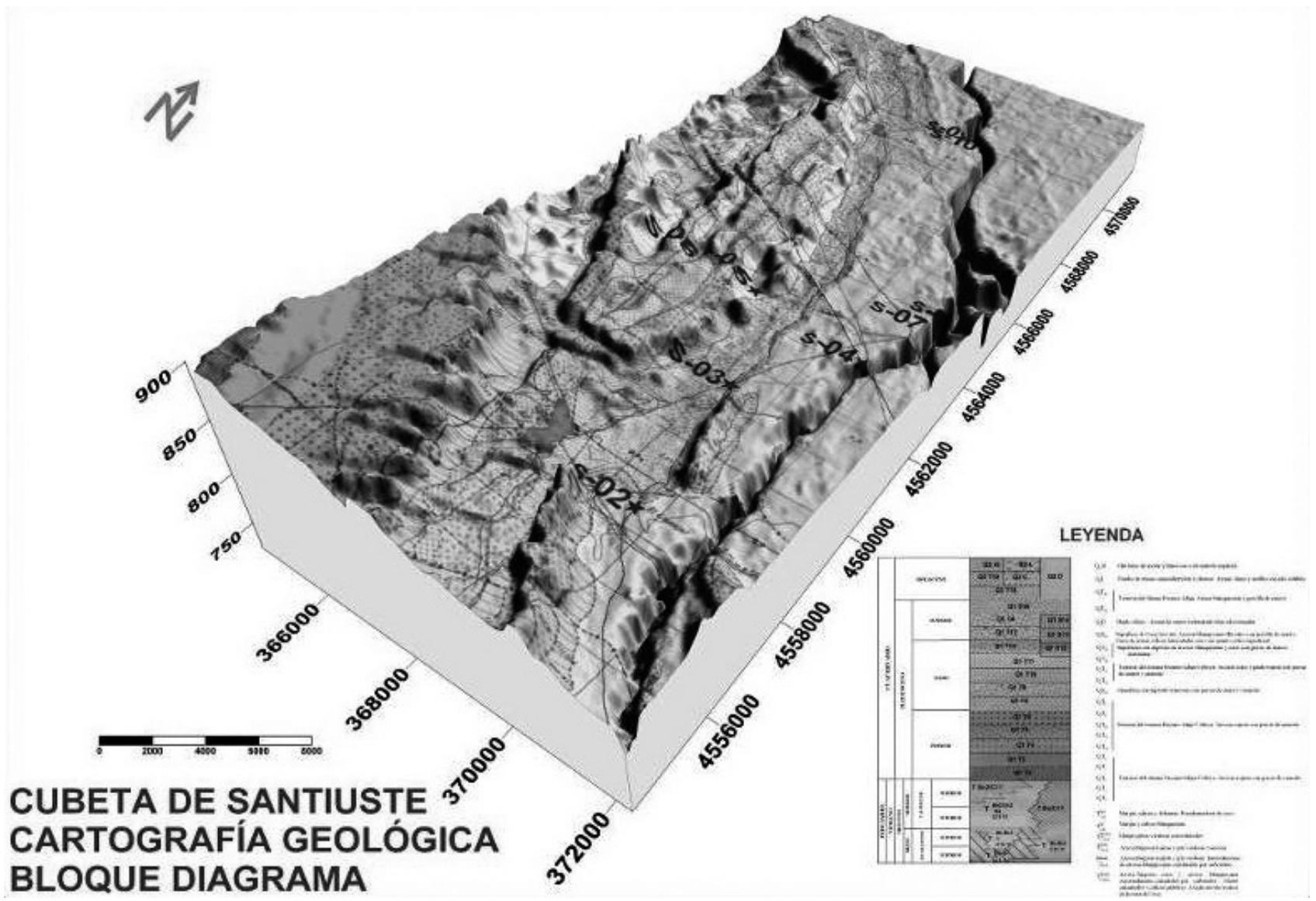

Figura 11. Cartografía geológica sobrepuesta al bloque diagrama para ganar expresividad y puntos de interés hidrogeológico s-01 a s-10. Modificado de Fernández-Escalante, 2005.

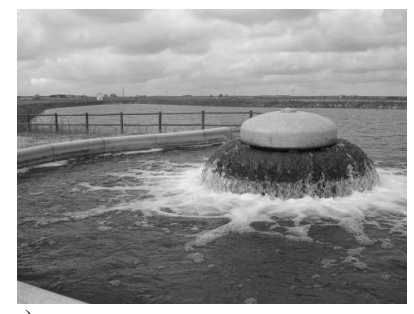

a)

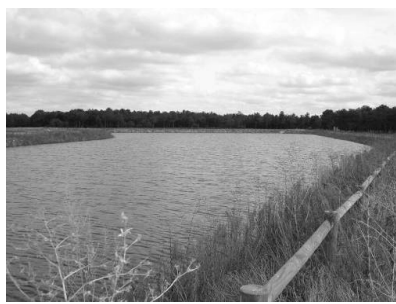

b)

Figuras 12 a) y b). Inicio del dispositivo y balsa de decantación de la que parten los canales. Fotografías tomadas por los autores.

En primer lugar, cabe anticipar la constatación en campo de manera inmediata de la distribución irregular y heterogénea de la colmatación, lo que resulta indicativo de la elevada complejidad del proceso y de la necesidad de emplear cuantas más técnicas sea posible para su detección y estudio.

Como ya se ha indicado en los apartados anteriores, se abordan de manera desglosada las actuaciones en balsas y en canales de infiltración.

\subsubsection{Balsas}

La primera tripleta corresponde a una escala general y tomas realizadas entre las 9 y 10 de la mañana. En general se ha optado por la toma de termografías en las primeras horas de la mañana con objeto de obtener contrastes altos en la capacidad térmica (propiedad de un material para absorber y almacenar calor, es decir, relación entre el calor que absorbe y su temperatura). La pretensión es que los materiales se encuentren en un estado inestable previo al equilibrio térmico regido por la segunda ley de la termodinámica. No obstante algunos autores consideran la primera hora de la tarde el momento más propicio para la toma de imágenes térmicas, tras alcanzar el equilibrio térmico (Flir Systems, 2005 y Fluke, 2009).

Estos pares fotografía-termografía del fondo de una balsa de infiltración (estación IN-0) han sido tomados en la transición entre la zona de fondo plano y labrada, tomando además los muros de escollera al pie del talud y detalle de los caballones.

En la Figura 13a cabe destacar la dualidad entre las crestas y los surcos del fondo de la balsa, con fuertes contrates térmicos originados por el arado al realizar los caballones, a pesar de que la presencia de vegetación interfiere en la firma térmica y, por tanto, en el análisis e interpretación.

En general, las arenas eólicas de las crestas presentan un 
Tabla 1. Resumen de los ocho ciclos de recarga artificial en la Cubeta de Santiuste. Datos y cálculos propios del proyecto de I+D+i DINA-MAR (mediciones hasta el 20/05/2010). En DINA-MAR, 2010.

\begin{tabular}{cccccccccc}
\hline Vol. infiltrado & $\begin{array}{c}\text { Precip. total } \\
\text { ciclo }(\mathbf{m m})\end{array}$ & $\begin{array}{c}\text { Fecha inicio } \\
\text { ciclo }\end{array}$ & $\begin{array}{c}\text { Fecha final } \\
\text { ciclo }\end{array}$ & $\begin{array}{c}\text { Días de } \\
\text { func. }\end{array}$ & $\begin{array}{c}\text { Q deriv } \\
\left.\mathbf{( h m}^{\mathbf{3}}\right)\end{array}$ & $\begin{array}{c}\text { Qm canal } \\
\mathbf{( 1 / \mathbf { s } )}\end{array}$ & $\begin{array}{c}\text { Vol. inf. Tot. } \\
\left.\mathbf{( h m}^{\mathbf{3}}\right)\end{array}$ & $\begin{array}{c}\text { \% vol inf/Q } \\
\text { derivado }\end{array}$ & $\begin{array}{c}\text { Oscilación media } \\
\text { n.f. (m) }\end{array}$ \\
\hline $2002 / 03$ & 291.4 & $05 / 12 / 2002$ & $01 / 05 / 2003$ & 148 & 3.50 & 278 & 1.3 & 37.14 & 2.3 \\
$2003 / 04$ & $\mathrm{n} / \mathrm{a}$ & $10 / 10 / 2003$ & $01 / 04 / 2004$ & 175 & 2.25 & 149 & 1.8 & 80 & 2.1 \\
$2004 / 05$ & $\mathrm{n} / \mathrm{a}$ & $01 / 10 / 2004$ & $01 / 05 / 2005$ & 212 & 1.26 & 68 & 0.97 & 76.98 & 1.17 \\
$2005 / 06$ & 305.4 & $15 / 11 / 2005$ & $01 / 04 / 2006$ & 137 & 5.11 & 372 & 3.56 & 69.67 & 3.36 \\
$2006 / 07$ & 331 & $01 / 10 / 2006$ & $01 / 05 / 2007$ & 212 & 12.68 & 692 & 12.19 & 96.13 & 3.57 \\
$2007 / 08$ & 203.4 & $30 / 05 / 2008$ & $06 / 06 / 2008$ & 8 & 0.53 & 902 & 2.5 & 87.41 & 0.31 \\
$2008 / 09$ & 85 & $01 / 11 / 2008$ & $30 / 04 / 2009$ & 181 & 3.88 & 248 & 1.62 & 64.5 & 0.62 \\
$2009 / 10$ & 89.2 & $17 / 02 / 2010$ & $31 / 03 / 2010$ & 43 & 0.71 & 191 & 2.13 & 228.59 & 0.41 \\
\hline
\end{tabular}

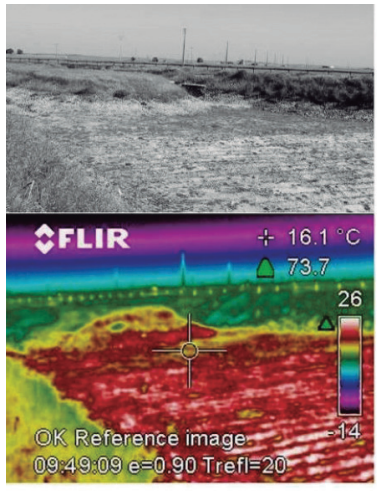

a)

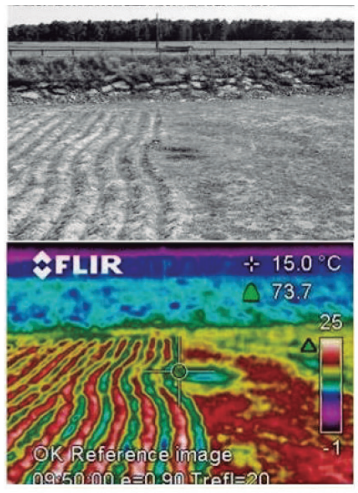

b)

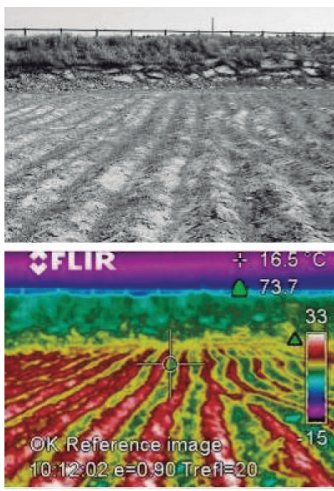

c)

Figuras 13. a) a c). Comparación entre los aspectos de cada fotografía normal y su imagen térmica correspondiente tomadas en la balsa de infiltración de cabecera del dispositivo de gestión de la recarga. Los termogramas se incorporan en el margen derecho de las imágenes radiométricas. Tomadas por los autores.

tono (firma térmica) más tenue y menor absorción de calor (y por tanto irradiación) que los surcos, donde se concentran abundantes partículas finas (gran parte correspondientes a colmatación física de forma predominante) con tonalidad, en general, más oscura y patrones de calor más cálidos.

El elemento de obra del centro de la fotografía corresponde a una parada con vertedera (inicio del canal Oeste) de hormigón prefabricado. En este caso su firma presenta una capacidad térmica inferior a la del terreno natural y a la de las rocas de la escollera.

La Figura 13b corresponde al extremo oeste de la balsa. Las tomas fueron obtenidas a las dos horas de amanecer aproximadamente.

La misma termografía resulta indicativa de la microtopografía del fondo del canal, permitiendo diferenciar pequeñas convexidades y concavidades en el fondo. En la pequeña cubeta presente en el centro del campo de visión instantáneo del par central, se aprecia además una serie de anillos concéntricos de firma térmica clara, indicativa de variaciones de humedad, acompañados de un desarrollo concéntrico de vegetación.

Se aprecia un contraste entre el muro de escollera (derecha) y el talud natural de acceso al fondo de la balsa para operaciones de mantenimiento (izquierda). A pesar de tener un ángulo de insolación bastante parecido, las arenas sueltas están absorbiendo más calor que las rocas de la escollera. La presencia de vegetación más desarrollada condiciona este aspecto de manera remarcable.

El muro de escollera del talud, constituido por esquistos grises moteados, presenta un rango térmico más estrecho, con variaciones en su firma atribuibles a contrates cromáticos de la propia roca, con capacidades térmicas ligeramente distintas, y a la vegetación desarrollada.

El par de la Figura 13c expone un perfil de caballones, con una distribución de procesos colmatantes y de vegetación bastante alineada con los surcos. A lo largo de estos hay variaciones significativas de vegetación y de humedad, aparentemente de origen microtopográfico. Cabe destacar que estas instantáneas se tomaron apenas tres semanas después de terminar el octavo ciclo de recarga artificial, la humedad edáfica es alta al igual que los niveles freáticos.

Los caballones presentan un grado de calentamiento diferente, en gran medida atribuible al ángulo en que han sido realizadas ambas tomas y al efecto de las sombras. A medida que aumenta la perspectiva, los contrastes son menores. Este hecho resalta la importancia de estudiar el campo de visión y el ángulo de toma fotográfica más adecuado. Generalmente las perspectivas en alzado muestran patrones térmicos más contrastados. Las tomas a 
primera hora de la mañana presentan abundantes sombras, dificultando la interpretación.

En todos los patrones resulta determinante la presencia de vegetación, cuya firma térmica contrasta con la temperatura de fondo reflejada, especialmente si el "blanco" es arenoso, con capacidades térmicas altas y firmas cálidas. En el caso de concentraciones de finos, las firmas térmicas quedan situadas en la parte superior-central del termograma (verdes y azules).

La presencia de vegetación herbácea se manifiesta en el campo de visión instantáneo como blancos de baja emisividad, ocupando posiciones medias a bajas en el termograma. Como consecuencia de su tamaño emite escasa energía infrarroja, por lo que apenas queda registrada en el patrón (ocupa uno o muy pocos pixeles en la imagen térmica), escapando al rango de detección de la matriz del termograma. Si la vegetación presenta un desarrollo más notable se manifiesta con colores pasteles y amarillos.

El hecho de que la vegetación herbácea se distribuya de manera heterogénea conforme a la humedad superficial y subsuperficial del sustrato trae consigo problemas de resolución espacial y dificultades para resolver los detalles, si bien localiza la humedad de mayor permanencia.

La escollera presenta una tonalidad diferente, al haber sido tomada la termografía a una hora posterior, tal y como denota la tonalidad más cálida, con mayor incidencia de la radiación solar en el talud. Esto también afecta a los resultados de la termografía y se debe prestar una atención especial al considerar los resultados de zonas soleadas frente a zonas sombreadas.

La siguiente tripleta corresponde a campos de visión instantáneos (IFOV) con mayor grado de detalle (Figuras 14).

La Figura 14a corresponde al cake superficial alrededor de un "testigo" en la cabecera de la balsa de decantación. Se trata de una zona de fondo plano en la que la colmatación física aparece asociada con vegetación herbácea. La presencia de grietas de desecación y el hecho de que las placas de arcilla aparezcan combadas por el calor provoca una diferencia de matices cromáticos en los propios encostramientos, adicionales a los provocados por efecto de las sombras. A tenor de las experiencias análogas, la presencia de cambios en el sustrato e incluso de aire entrampado en la zona más superficial influye en la cromatografía. Además se aprecia una clara influencia de la microtopografía, con zonas de elevada humedad y evapotranspitración, con firmas cromáticas tenues (sectores superior derecho y central del termograma).

La Figura $14 \mathrm{~b}$ corresponde al detalle de unos caballones en el fondo de la balsa de decantación, por tanto un suelo arenoso suelto con una costra de colmatación. El termograma indica una mayor amplitud en la temperatura radiométrica que en el caso precedente, con un rango de 13 a $33^{\circ} \mathrm{C}$. La fotografía pone de manifiesto que el cake superficial no se concentra exclusivamente en los surcos entre los caballones, también hay costras depositadas sobre las crestas, habida cuenta de su génesis sumergida. El par muestra además unas diferencias cromáticas importantes entre los procesos colmatantes y la vegetación, lo que posibilita sudiferenciación. El patrón térmico para condiciones ambientales análogas indica que las firmas más importantes para la detección de procesos colmatantes se encuentren en la franja entre el azul y amarillo. Las costras más expuestas a insolación presentan tonos rojizos y granate-naranja en zonas de sombra.

La Figura 14c muestra cómo la perspectiva en que sean tomadas las termografías es determinante. Una toma oblicua está aportando menos información que una en alzado. Aunque el rango del termograma sea superior, es debido a que el calor irradiado más alto procede del técnico de toma de datos. Especial atención requieren las sombras, que pueden ser evitadas con el sol en posición cenital. Los procesos colmatantes manifiestan en este caso una firma cromática cálida, cuyo calentamiento se debe a su tonalidad más oscura; si bien la absorción de calor por los materiales es tan alta que apenas se pueden apreciar contrates. No
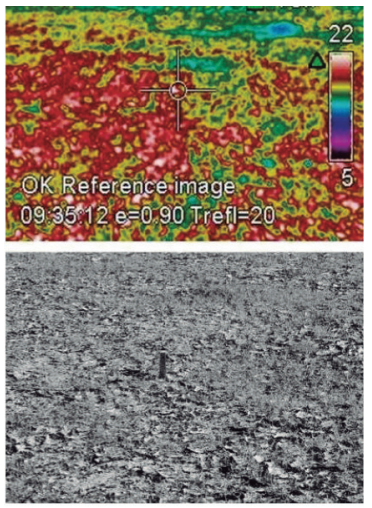

a)

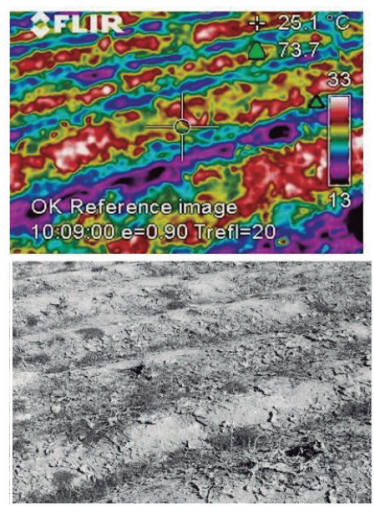

b)

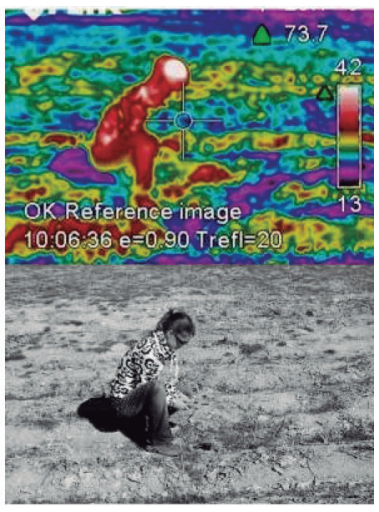

c)

Figuras 14 a) a c). Tripleta de pares constituidos por de una fotografía normal y una imagen radiométrica o termografía que permiten comparar aspectos relativos a la distribución de litosomas y su imagen térmica en la balsa de infiltración de cabecera del dispositivo de gestión de la recarga a escala de detalle. 
obstante, su capacidad térmica es sobrepasada por materiales más claros tras un período de insolación más claro. Esto dificulta el diseño de la paleta cromática dependiendo de la hora de toma de las imágenes radiométricas, y por supuesto, de las condiciones ambientales.

Las Figuras 15 corresponden a dos perfiles de un caballón superficial a distinta escala. Las tomas se realizaron inmediatamente después de la excavación de las catas, con objeto de evitar el calentamiento del material recientemente al descubierto.

Nuevamente se aprecia un fuerte contraste entre los procesos colmatantes, la vegetación, el terreno natural descubierto y el cake superficial, que a esta escala presenta distinta tonalidad termográfica en alzado y perfil. Es apreciable también el perfil de humedad del suelo, cuya amplitud abarca la mitad del termograma, desde tonos oscuros a amarillos, con temperaturas más bajas en el fondo y paredes de la calicata.

La presencia de sombras hace recomendable trazar las calicatas teniendo en cuenta la posición del sol, preferentemente de manera transversal al caballón.

Estos contrastes (analizando y corrigiendo el efecto de las sombras) permiten corroborar las efectividad de los caballones, ya que se aprecia un desarrollo de procesos más elevado en valles que en montículos, con mayor espesor de costra en los surcos que, a su vez, varía a lo largo de cada surco. También es patente la presencia de depósitos de cake incluso sobre las crestas, aunque con menor espesor y una fracción arenosa más alta.

Las variaciones térmicas en los surcos se deben, bien a diferencias de altura, de vegetación-humedad, y/o a la aparición en superficie de procesos orgánicos y físicos, con tonalidad más oscura en general y mayor capacidad térmica.

\subsubsection{Canales}

Las Figuras 16 a y b corresponden a sectores del canal
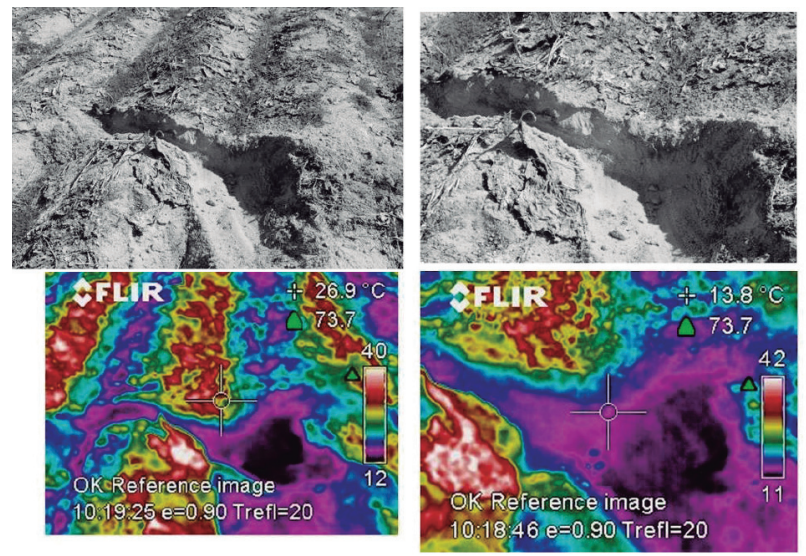

a)

b)

Figuras 15 a) y b). Pares fotografía-termografía del perfil de un caballón del fondo de la balsa de decantación realizado mediante una calicata superficial. Termografía tomada con inmediatez a la excavación. 11h, 20 de junio de 2010. Tomadas por los autores. con talud inicial 1/1 y relativamente vegetados. En la parte inferior, correspondiendo con la zona que queda inundada, el talud ha ganado verticalidad al erosionarse. Los sedimentos se concentran en el fondo del canal, fosilizando procesos colmatantes (extremo superior de la figura 16a) o bien entremezclándose con ellos. Esta morfología es indicativa del calado (altura del agua dentro del canal durante la recarga) y presenta distintas coloraciones conforme a la inclinación del talud, formando franjas subparalelas a la altura con fuerte influencia de la humedad y de las sombras.

El fondo del canal presenta el mayor desarrollo de vegetación herbácea, que se mantiene fresca por efecto de la humedad bajo el fondo del canal y, previsiblemente, por los nutrientes aportados por los procesos colmatantes físicos y biológicos.

Las Figuras $16 \mathrm{c}$ y $16 \mathrm{~d}$ corresponden al canal Este, de talud $2 / 3$ y cuatro años más de operatividad, por lo que el desarrollo radicular de la vegetación es superior al caso precedente. El canal está más encajado y por él circula un caudal inferior.

La Figura 16c pone de manifiesto que las arenas sueltas labradas en superficie (extremo superior izquierdo) absorben (e irradian) más calor que el camino compactado (superior derecha). La vegetación a lo largo del talud es de dos tipos; la más cercana a la coronación del talud es más afín con los cultivos de la zona, con frecuentes plantas nitrófilas; mientras que la más cercana a la orilla de la lámina circulante es de aspecto ripario, más verde y fría. La propia lámina presenta zonas diferentes por presencia de vegetación y por generación de islas de calor y frío, atribuibles a la turbulencia del agua, tal y como se presentó en la Figura 7. Es posible además que la clorofila en el agua tenga una firma térmica disociable, y cuyo tema constituye un objeto de estudios posteriores.

Las escasas zonas del talud sin vegetación tienen una elevada absorción térmica. Se ha comprobado en campo la reacción ante el ácido clorhídrico de estos sectores del talud. Esta es atribuible a la precipitación de calcita en las paredes, especialmente en zonas por las que ha circulado agua, y actualmente se encuentra en zonas del talud generalmente abruptas. Este hecho complica una vez más el fenómeno, dada la presencia de colmatación química en forma de precipitación de calcita, cuyo grado de absorción de calor es alto a pesar de su tonalidad más clara que el terreno circundante (teniendo en cuenta la presencia de zonas más frías por efecto, sombra y vegetación).

La Figuras 17 a y $17 \mathrm{~b}$ ponen de manifiesto en el perfil del canal la altura de la lámina de agua, tanto por termografía como por la morfología del talud, con un cambio brusco en la inclinación. Otra observación patente es el trazado sinusoidal de las líneas semiparalelas que circunscriben a la colmatación y que se aprecian a ambos lados del fondo del canal. Se trata de una sectorización por similitud mediante criterios visuales que pone de manifiesto, una vez más, la distribución irregular de la vegetación, la diferente capacidad térmica del cake por su espesor $\mathrm{y}$, con seguridad, 

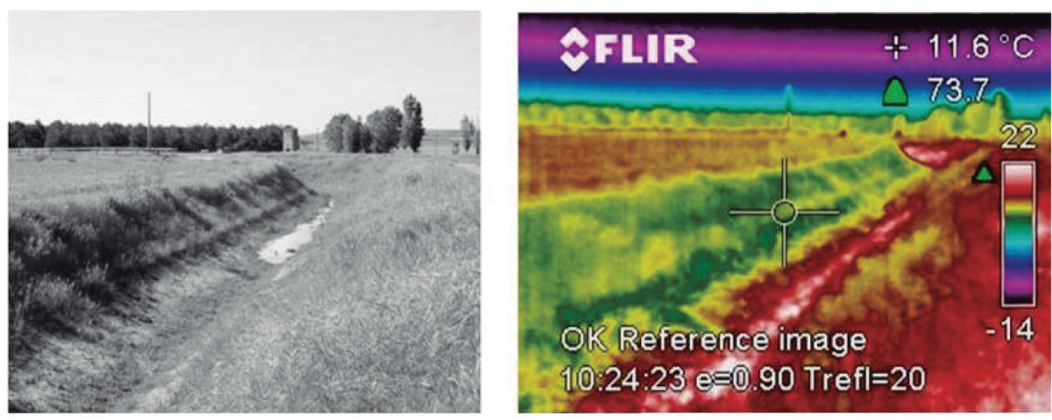

a)

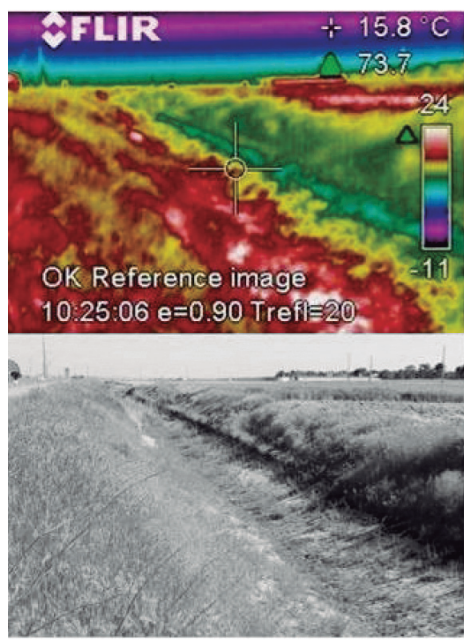

b)
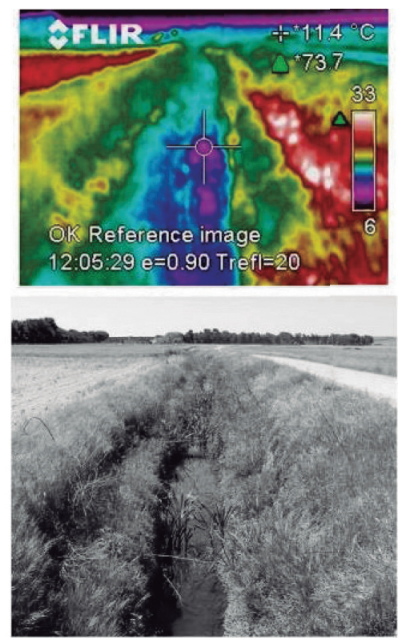

c)
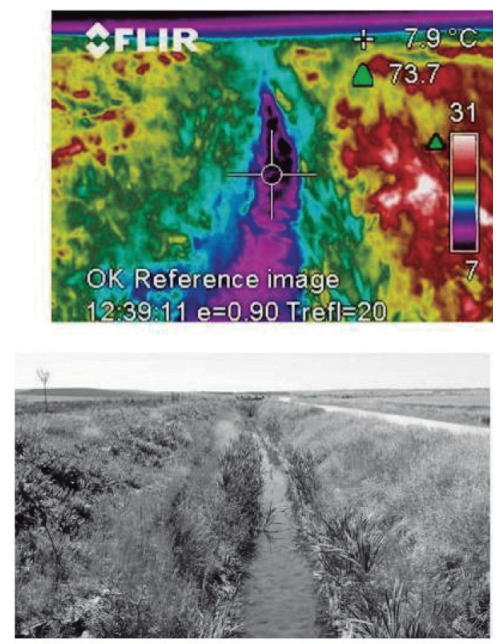

d)

Figuras 16 a) a d). Pares fotografía normal-termografía de distintos sectores de dos canales de recarga artificial; a) y b) Canal Oeste, sector Sur del dispositivo sin agua circulante; c) y d) Canal Este, sector central, de diferente anchura, calado y talud, al término de un ciclo de recarga. Tomadas por los autores.

la heterogeneidad y anisotropía a escala de detalle de un acuífero considerado tradicionalmente isótropo.

La presencia de vegetación introduce tonos fríos en el perfil, al igual que el cake depositado en el fondo, que se presenta en láminas de distinto espesor y entremezclado con sedimentos desprendidos de las paredes. En el fondo se puede diferenciar, además, los tramos donde hay geotextiles enterrados, que dan tonos más fríos, de aquellos de terreno natural (extremo superior de ambas fotografías), con presencia más escasa de cake superficial.

La termografía guarda cierta correlación con sectores con presencia de calcita precipitada, constatada en campo mediante ácido, si bien las tonalidades varían escasamente.

La aparición del cielo en las termografías amplía el rango del termograma hasta temperaturas bajo cero, por lo que se debe evitar en estudios de detalle, salvo que se pretenda disociar tipos de nubes u otras circunstancias ambientales.

\subsection{Distribución de los procesos colmatantes por su naturaleza}

De acuerdo con el estudio de los materiales en el fondo de los dispositivos, de las probetas y perfiles de colmatación, se ha llevado a cabo una caracterización de la zona de estudio basada en el predominio de determinados procesos.

Se han diferenciado cuatro tipologías de colmatación predominante bien diferenciadas: física, química, biológica y bioquímica.

El proceso colmatante más frecuente es el físico (Tabla 2), habida cuenta del origen fluvial de las aguas de recarga, dado que las operaciones de filtrado y decantación a veces han sido inefectivas. Presenta especial desarrollo al inicio de ambos canales y en el sector central del canal Oeste.

La colmatación química carbonatada aparece en el sector Norte del canal Oeste y en el central-Norte del sector Este. Los procesos oscuros asociados a ambientes reductores se han detectado en la zona central Este del dispositivo, donde las arenas tienen abundante pirita diagenética tipo placer (pepitas).

Se ha detectado una mayor concentración de procesos colmatantes biológicos en zonas con escaso espesor de acuífero y proximidad del sustrato margoso (menos de cinco metros de profundidad) y niveles freáticos altos (sector surcentral del canal Oeste).

El vertido de aguas de la depuradora de Santiuste, por lagunaje, al canal de recarga artificial genera en sus 

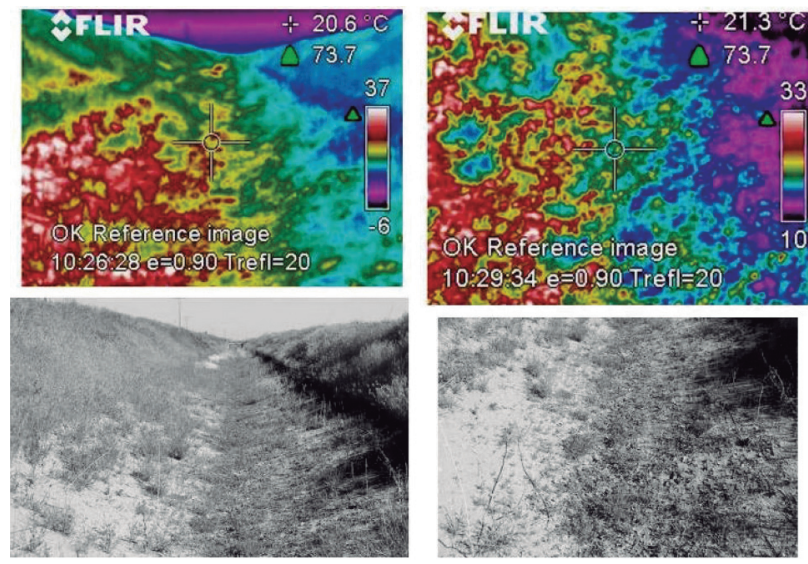

a)

b)

Figuras 17 a) y b). Fondo del canal Oeste en una zona con geotextiles enterrados para el estudio de procesos (parte inferior) y la transición hacia el terreno natural (mitad superior de la Figura a y extremo de la b). Sector sur del dispositivo. Tomadas por los autores.

proximidades un estrato de fangos orgánicos de hasta 15 $\mathrm{cm}$ de espesor. Estos aparecen recubiertos por lemnáceas, debido a su alta carga en nutrientes.

Se han detectado retículas o marañas de algas, en general azules filamentosas, en el sector central oeste del dispositivo. $\mathrm{Su}$ génesis es atribuida a procesos bioquímicos.

La estación IV-5 se considera "mixta" al coexistir todos los tipos de procesos.

Conforme a la distribución espacial de los procesos dominantes y sus combinaciones detectados en campañas de campo y clasificados, se propone una cartografía inicial para su caracterización para la situación de febrero de 2010 (Figura 18). Esta cartografía previsiblemente presentará variaciones importantes a lo largo del tiempo a medida que prosperen los procesos colmatantes y aumente la efectividad de la depuradora.

\section{Conclusiones}

Estas conclusiones deben ser consideradas propias de una etapa inicial, al tratarse de una línea de acción con poco más de un año de desarrollo. El apartado incluye además recomendaciones prácticas conforme a la experiencia adquirida.

Se ha propuesto una caracterización de la colmatación en la Cubeta de Santiuste, en el acuífero de los Arenales, con presencia de los principales tipos de colmatación y sinergismos por combinación de procesos. Las técnicas convencionales de detección se han complementado con técnicas óptico-electrónicas de validación.

La aplicación de técnicas termográficas en hidrogeología permite un acercamiento a la determinación de la porosidad de los materiales y de la evaporación de agua a su través mediante técnicas indirectas. Incluso las variaciones de tonalidad permiten "visualizar" la
Tabla 2. Propiedades de los perfiles en calicata y determinación de los procesos colmatantes mayoritarios detectados en las estaciones de estudio de la colmatación. Realizado por los autores.

\begin{tabular}{|c|c|c|c|}
\hline EST & $\begin{array}{l}\text { Fecha de } \\
\text { muestreo }\end{array}$ & $\begin{array}{l}\text { Proceso colmatante } \\
\text { principal }\end{array}$ & Observaciones \\
\hline IN-0 Are & $01 / 08 / 2007$ & Físico & Perfil bandeado \\
\hline IN-0 Arc & $01 / 08 / 2007$ & Cake + físico & $\begin{array}{c}\text { Costra superficial en } \\
\text { depresiones }\end{array}$ \\
\hline IN-1 & $28 / 08 / 2007$ & Cake+físico & $\begin{array}{c}\text { Cake determinado por } \\
\text { topografía }\end{array}$ \\
\hline $\mathrm{IN}-2$ & $28 / 08 / 2007$ & Físico & $\begin{array}{l}\text { Arena empastada por } \\
\text { topografía }\end{array}$ \\
\hline IN-3 & & Cake + físico & \\
\hline IN-4 & & Físico & $\begin{array}{c}\text { Arena empastada por } \\
\text { topografía }\end{array}$ \\
\hline IN-5 & $28 / 08 / 2007$ & Físico-biológico & $\begin{array}{l}\text { Arcilla y materia orgánica } \\
\text { abundante }\end{array}$ \\
\hline IN-6 & & Físico-biológico & $\begin{array}{l}\text { Maraña de algas, arcilla y } \\
\text { materia orgánica }\end{array}$ \\
\hline IN-7 & $28 / 08 / 2007$ & Cake+biológico & $\begin{array}{l}\text { Cake y materia orgánica } \\
\text { diferencia horizonte A }\end{array}$ \\
\hline IN-8 & $01 / 08 / 2007$ & Físico-biológico & Cake y perfil bandeado \\
\hline IN-9 & & Físico-biológico & Cake y materia orgánica \\
\hline IN-10 & $01 / 08 / 2007$ & Físico-biológico & Cake y materia orgánica \\
\hline IN-11 & $01 / 08 / 2007$ & Químico & $\begin{array}{c}\text { Cake, carbonatos y } \\
\text { materia orgánica }\end{array}$ \\
\hline IV-1 & $01 / 08 / 2007$ & Físico & Perfil bandeado \\
\hline IV-2 & $28 / 08 / 2007$ & Biológico-físico & $\begin{array}{c}\text { Materia orgánica y } \\
\text { lemnáceas }\end{array}$ \\
\hline IV-3 & $28 / 08 / 2007$ & Biológico-físico & $\begin{array}{l}\text { Materia orgánica y } \\
\text { lemnáceas }\end{array}$ \\
\hline IV-4 & $28 / 08 / 2007$ & Físico-biológico & Materia orgánica \\
\hline IV-5 & $01 / 08 / 2007$ & Mixto & $\begin{array}{l}\text { Cake, arcillas, vectores } \\
\text { biologicos y carbonatos }\end{array}$ \\
\hline IV-6 & $28 / 08 / 2007$ & Físico-biológico & $\begin{array}{l}\text { Cake, materia orgánica y } \\
\text { carbonatos }\end{array}$ \\
\hline IV-7 & $28 / 08 / 2007$ & Biológico-físico & $\begin{array}{c}\text { Horizonte A de materia } \\
\text { orgánica y arcilla }\end{array}$ \\
\hline
\end{tabular}

evapotranspiración en suelos vegetados. Esta afirmación se basa en que toda superficie verde, por pequeña que sea, disminuye la temperatura respecto al entorno gracias a la evapotranspiración.

También el color de materiales similares modifica el comportamiento térmico de la superficie. Se trata de un principio de la termografía básico que cobra complejidad al apreciar que materiales del mismo color presentan un grado de absorción de calor diferente. Los materiales aparentemente homogéneos con diferente respuesta termográfica parecen responder a cambios de la humedad, de vegetación, características heterogéneas de su sustrato a una profundidad cercana, incluso de aire entrampado y distinto comportamiento hidrodinámico.

La técnica del análisis de imágenes radiométricas aporta más información relativa a variaciones de las propiedades de los suelos y de su composición que la que aporta sobre la distribución de los procesos colmatantes. No obstante, puede ser considerada una técnica "indicial" para localizar y estudiar zonas con diferente grado de colmatación, y por ende, diferente permeabilidad.

La concentración de finos suele obedecer a criterios de microtopografía. Así mismo suele ir acompañada de un 


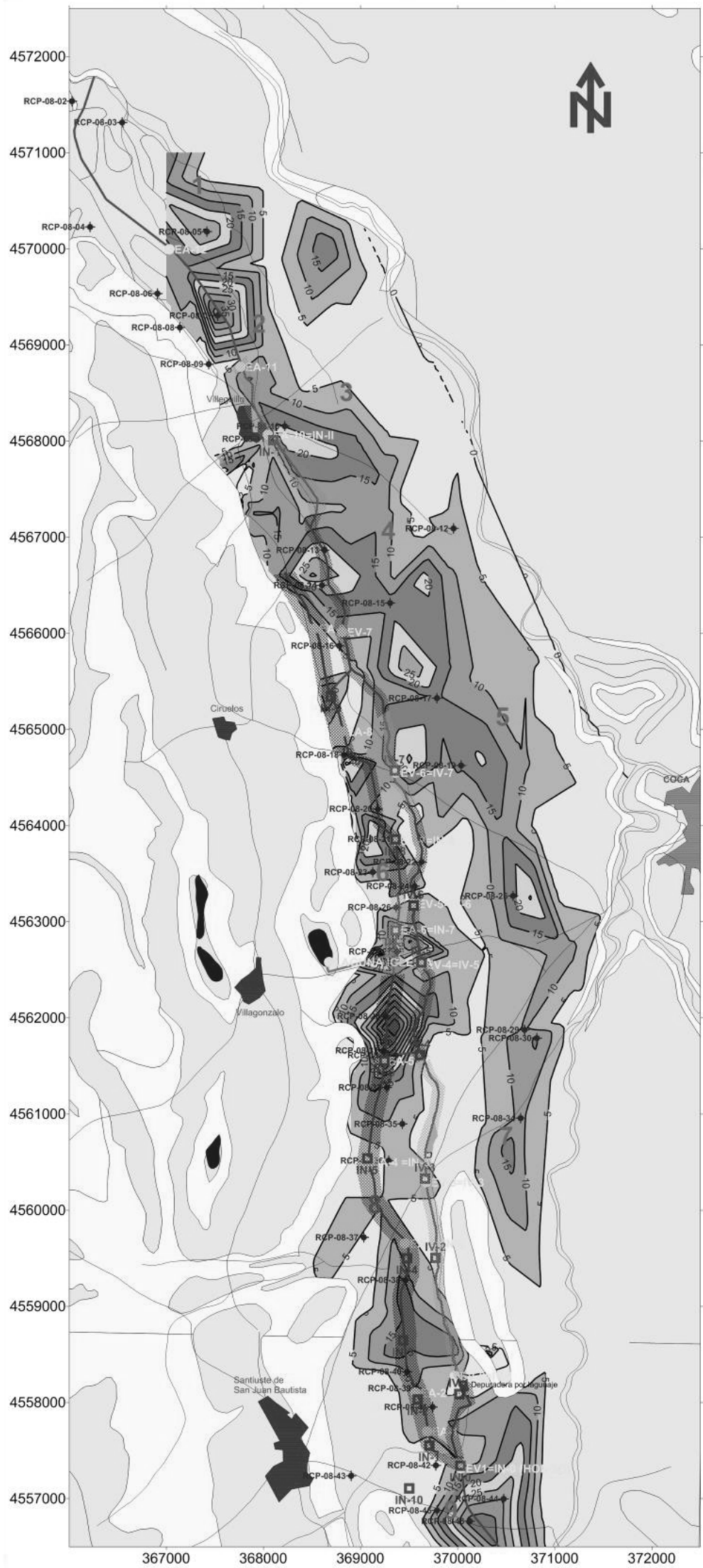

CUBETA DE SANTIUSTE

DISTRIBUCIÓN DE LOS

PROCESOS COLMATANTES Y POSICIÓN DE LAS ESTACIONES DE CONTROL $7^{\circ} \mathrm{CICLO}$ DE M.A.R. 2009/10

\section{Espesor del acuífero eólico cuaternario $(\mathrm{m})$}
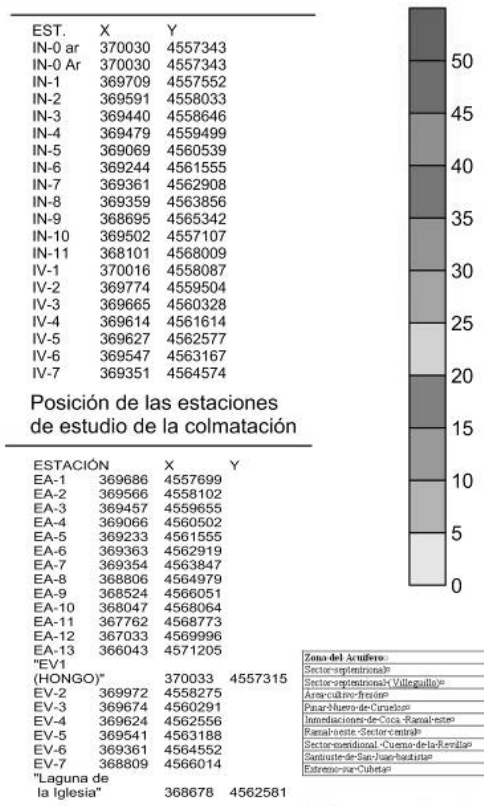

Posición de las estaciones Valores medios de

de control de la calidad.

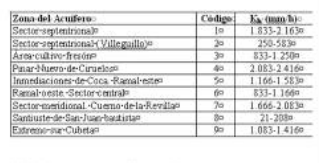
permeabilidad.

\section{FEBRERO DE 2010}

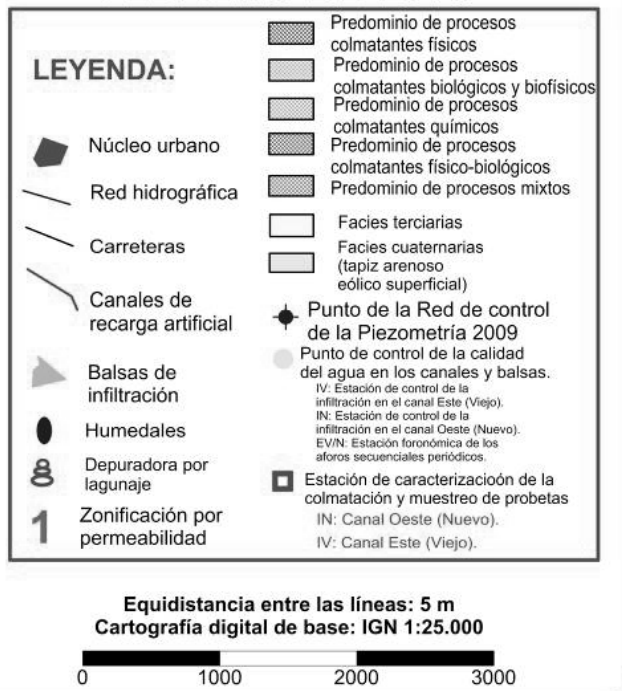

Figura 18. Cartografía con el trazado de los canales de recarga gestionada y la distribución de los procesos colmatantes predominantes por su naturaleza. El mapa presenta además las facies geológicas, la posición de los ensayos de infiltración y determinación de parámetros inestables, de los puntos de la red de control de la piezometría y otros elementos singulares. Escala gráfica 1:25000. Realizado por los autores 
mayor desarrollo de vegetación herbácea, que se mantiene fresca por efecto de la humedad bajo el fondo del canal $\mathrm{y}$, previsiblemente, por los nutrientes aportados por los procesos colmatantes físicos y biológicos.

Los procesos colmatantes físicos y biológicos se distribuyen de manera homogénea por el fondo de las balsas inundadas. Se ha detectado la presencia de cake incluso en las crestas de los caballones, si bien el espesor es muy inferior al registrado en los surcos. Estos procesos se retiran por remoción, pero los químicos y algunos biológicos siguen actuando, hasta el punto de conducir hasta el abandono de muchas obras de infiltración.

La ejecución de calicatas en el fondo de balsas y canales debe realizarse teniendo en cuenta su orientación con respecto a la posición del sol y se debe evitar el calentamiento del material recientemente destapado, procediendo a la toma de datos y de termografías con rapidez.

Los procesos químicos más frecuentes se han detectado en el canal Oeste en forma de precipitados de calcita, cuya tonalidad es más blanquecina y su respuesta termográfica es opuesta a la habitual de los procesos físicos y biológicos. Estos precipitados de calcita aparecen tanto en el fondo de los canales como en forma de "manchas" en los taludes, generalmente en la zona que queda sumergida y en la de oscilación de la lámina de agua que circula en el canal. Su grado de absorción de calor es alto, a pesar de su tonalidad clara y su elevada reflexión de los rayos solares, lo que contrasta con el terreno alrededor y facilita su localización. Estas zonas no se han detectado en el talud de las balsas por tener muros de escollera, pero sí en el fondo.

La hora para realizar las termografías más adecuada debe ser planificada conforme a los fines previstos:

- A primera hora de la mañana los materiales han sido calentados ligeramente y los contrates son fuertes, lo que permite disociar con detalle, si bien hay numerosas sombras que dificultan la interpretación.

- En días completamente nublados las firmas térmicas presentan altos contrastes y el resultado no se ve alterado por zonas de sol y sombra.

- A primera hora de la tarde el calentamiento es mayor y hay un mayor equilibrio entre los materiales conforme a su "propia" capacidad térmica. En este caso los contrastes son menores, pero también lo son las sombras. Esta hora es más propicia para fines tales como detectar fugas en conducciones por cambios de humedad, detección de sectores del acuífero con tasas de infiltración bajas y mayor calentamiento de las aguas, etcétera.

El cake superficial de los procesos colmatantes irradia calor según su tonalidad y espesor, pero su capacidad térmica es inferior a la de otros materiales, como las arenas sueltas, tras varias horas de calentamiento. De ahí la preferencia por tomar imágenes radiométricas a primera hora de la mañana, aunque las citas bibliográficas mencionan la primera hora de la tarde como la más apropiada "en general".

La técnica está dando buenos resultados para detectar puntos con humedad anormal en fondo o pared (firma térmica clara) y para detectar zonas con fugas de aire (firma térmica tenue). No obstante, la firma térmica es más cálida sobre cámaras de aire o zonas con acumulación de aire importante entrampado en poros del acuífero cerca de la superficie.

Los litosomas y materiales presentes en la zona de trabajo que presentan distinta capacidad térmica (adquieren una temperatura mayor bajo condiciones similares de espesor y con tonalidades semejantes), y, en consecuencia, distinto comportamiento termográfico.

Estudiando los termogramas de los distintos "blancos" de las imágenes radiometrizadas, se propone la siguiente paleta térmica o esquema de color para mostrar variaciones en los patrones térmicos (Tabla 3). Los valores menores son para el cielo y los más altos para la arena suelta, cuya superficie sometida a insolación es superior y retiene más aire en sus poros.

Dado que esta paleta comprende materiales bastante diferentes, la línea de acción debe avanzar diseñando paletas específicas para los procesos colmatantes, si bien éstas serán diferentes según la naturaleza del sustrato en que se desarrollen y otros factores ambientales.

Las sombras son fundamentales para reducir el calor de cualquier superficie, por lo que representan un factor a tener en consideración de cara a minimizar la evaporación de la lámina de agua en balsas.

Las sombras proporcionadas por vegetación arbustiva ofrecen sombra permanente y disminuyen la evaporación. Se debe analizar qué especies de arbustos "rompen" con su desarrollo radicular los procesos colmatantes subsuperficiales e incluso su capacidad para reducir la colmatación por asimilación. Este hecho abre la vía de valorización de los procesos colmatantes, especialmente los biológicos, lo que constituye una importante línea de investigación.

Tabla 3. Paleta térmica inicial para los distintos materiales de la Cubeta de Santiuste en las inmediaciones de sus dispositivos de recarga gestionada para la situación de febrero de 2010, base de futuras termografías comparativas en condiciones ambientales análogas que permitan definir tendencias térmicas a medida que prospere el desarrollo de la colmatación. El esquema de color se ha definido para termogramas con rangos térmicos medios. Realizada por los autores

\begin{tabular}{|c|c|}
\hline Materiales & Esquema de color \\
\hline Agua & Morado, rosa, azul, verde. \\
\hline Cultivos & Verde, amarillo \\
\hline Prefabricados de hormigón & Azul \\
\hline $\begin{array}{l}\text { Muro de escollera (esquistos } \\
\text { mesocráticos moteados) }\end{array}$ & Azules \\
\hline Arcilla húmeda & Azul, verde \\
\hline Arena vegetada & Verde, granate, amarillo \\
\hline Grava suelta / zahorra & Amarillo, granate \\
\hline Arena ligeramente vegetada & Naranja \\
\hline Arena compactada & Rojo \\
\hline Arena suelta & Blanco (rojo estallado) \\
\hline
\end{tabular}


Cualquier rastro de vegetación reduce de manera importante la temperatura superficial, incluso en su entorno más cercano.

Cabe destacar los problemas ocasionados por mediciones por encima de la resolución del sistema (blanco térmico muy pequeño o lejano), problemas de resolución espacial para discernir detalles, dudas sobre la fiabilidad por cambios en las condiciones ambientales, cuestiones relativas a la habilidad de los técnicos para interpretar los datos, la no detección de problemas o las recomendaciones erróneas o imprecisas motivadas por interpretación de las firmas térmicas.

En caso de obtener una amplitud del termograma (o leyenda) muy amplia, se puede evitar la aparición del cielo, porque amplía el rango hasta valores bajo cero.

El número de factores "contaminantes" que enmascaran la capacidad térmica específica de los distintos procesos es alto, por tanto cada técnico debe ser "cuidadoso" al interpretar las firmas térmicas.

Las técnicas termográficas aplicadas a la caracterización de los procesos colmatantes arrojan resultados coincidentes, en general, con la diferenciaciónpor otros métodos, proporcionando información adicional, como por ejemplo, precipitación química en las paredes del talud.

La cartografía relativa a la caracterización y distribución de los procesos colmatantes permitirá llevar a cabo estudios evolutivos a partir de ella y termografías comparativas.

La continuidad de esta línea de acción debe perseguir la consecución de una "paleta térmica" o esquema de color que permita definir los patrones térmicos y detectar las variaciones en la firma térmica a lo largo del tiempo que estén motivadas por cambios en el sistema suelo-acuíferoagua.

El conocimiento de la distribución de los procesos colmatantes proporciona unos criterios de selección idóneos para planificar operaciones tanto de diseño, como de limpieza y mantenimiento de los dispositivos de recarga gestionada de tipo superficial. Además los criterios de mantenimiento preventivos cobran una nueva dimensión, al incorporar a los programas otros de carácter "predictivo."

Aunque esta técnica no está tan desarrollada como para hacer mediciones cuantitativas, presenta una gran validez en cualitativas, abriendo una interesante línea de acción, en permanente mejora. En definitiva, aunque la técnica no es determinante, resulta de gran ayuda como complemento a otras metodologías de estudio.

\section{Agradecimientos}

La toma de datos y seguimiento precisos para elaborar este artículo se ha llevado a cabo en el marco de los proyectos de I+D+I DINA-MAR, 30/13.053 y GIAE, 30/13.513; SEPI-Grupo Tragsa, España.

\section{Referencias}

Asociación Española de Normalización y Certificación (AENOR), 1995, Calidad del agua. Muestreo: Guía para el diseño de los programas de muestreo (UNE-EN 25667), España.

Atsumi, K., 1973, Medical thermography, en Atsumi, K., (ed.): Tokio, Japón, University of Tokyo Press, 380 p.

De los Santos, R., Sánchez-Cabezas, F.J., 2011, La técnica de la termografía aplicada al campo de las patologías y filtraciones: España, PYCSA, Artículo, $12 \mathrm{p}$.

Depth Investigation of New Areas for Managed Aquifer Research (DINAMAR), 2010, La gestión de la recarga artificial de acuíferos en el marco del desarrollo sostenible. Desarrollo tecnológico: Serie Hidrogeología Hoy no 6, ISBN 978-84-614-5123-4, Grupo Tragsa. Grafinat, Madrid, 2010. $496 \mathrm{p}$.

Edmond, J., Morse, B., Richard, M., Stander, B., Viau, A., 2009, Surface Ice Observations on the St. Lawrence River Using Infrared Thermography, in Proceedings del $15^{\text {th }}$ Workshop on River Ice, St. John's, Newfoundland and Labrador, 15 a 17 de junio de 2009: CGU HS Committee on River Ice Processes and the Environment.

Fernández-Escalante, E., 2005, Recarga artificial de acuíferos en cuencas fluviales. Aspectos cualitativos y medioambientales. Criterios técnicos derivados de la experiencia en la Cubeta de Santiuste (Segovia): Universidad Complutense de Madrid, Tesis Doctoral, $1336 \mathrm{p}$.

Fernández-Escalante, E., 2009, Técnicas de tratamiento de suelo y acuífero (S.A.T.) aplicadas a la gestión de la recarga artificial: Serie Hidrogeología Hoy, Grafinat, 159 p.

Fernández-Escalante, E., García, J.M., Minaya, M.J., 2009, Propuestas para la detección y corrección de impactos producidos por procesos colmatantes en el dispositivo de recarga artificial de la Cubeta de Santiuste (Segovia): Boletín Geológico Minero, 120 (2), 215-234.

Fernández-Escalante, E., García-Merino, A., 2009, Estudio sobre la evolución de la zona no saturada en las inmediaciones de dispositivos de tipo superficial de gestión de la recarga de acuíferos, Las estaciones DINA-MAR ZNS, $1^{\text {er }}$ ciclo de operatividad: Estudios en la Zona no saturada del suelo. Vol IX. Barcelona, 18-20 de Noviembre, 2009.

Fernández-Escalante, A., E., García-Rodriguez, M., 2009, Gestión de la recarga artificial de acuíferos: España, M.A.R., Artículo, Serie Hidrogeología Hoy, Grafinat, 138 p.

Flir Systems, 2005, Therma-Cam E2. User's manual, version 1.3 ThermaCAM ${ }^{\mathrm{TM}}$. Danderyd, Suecia.

Fluke. Snell Group, 2009, Introducción a los principios de la termografía. ATP, Inc., 68 p.

Gayo Moncó, E., 2002, La humedad como causa de patologías en monumentos: desarrollo de nuevas técnicas de análisis no destructivo basadas en termografía infrarroja: Madrid, Universidad Complutense de Madrid, Facultad de ciencias físicas, Departamento de Física de Materiales, Tesis doctoral, $222 \mathrm{p}$

Hillson P.J., 1982, Early Thermographic Systems: The Journal of Photographic Science, 31, 252-262.

Hunt, E.R., Rock, B.N., 1989, Detection of changes in leaf water content using near and middleinfrared reflectances: Remote Sensing of Environment, 30, 43-54.

Instituto de Reforma y Desarrollo Agrario (IRYDA), 1990, Proyecto de Asistencia Técnica para el Estudio Hidrogeológico de la Cubeta de Santiuste (Segovia): Documento técnico no publicado disponible para consulta en la biblioteca del MAGRAMA, IRYDA-ITGE.

Lagouarde, J.P., 1983, Analyse des microclimats du Mont Ventoux par télédétection dans l'infrarouge thermique: mise au point d'une method d'étude de l'effet du relief sur les thermographies H.C.M.M.: Méditerranée Télédétection, 1-2, 3-10.

Lawrence, P., Golden, J., 1980, A Meso-Scale to Micro-Scale Evaluation of Surface Pavement Impacts to the Urban Heat Island-Aestas Hysteresis Lag Effect, Artículo del programa "Sustainable Materials and Renewable Technologies": Arizona, United States of America, Arizona State University, $64 \mathrm{p}$. 
Ministerio de Agricultura del Gobierno de España (MAPA), 1999, Proyecto de las obras para la recarga artificial del acuífero de los Arenales, Cubeta de Santiuste (Segovia).

Ministerio de Agricultura del Gobierno de España (MAPA), 2005, Asistencia técnica para el seguimiento y modelización de la recarga artificial en la Cubeta de Santiuste de San Juan Bautista (Segovia). Dirección General de Desarrollo Rural-TRAGSATEC (no publicado).

Ministerio de Obras Públicas, Transportes y Medio Ambiente (MOPTMA), 1994, Informe sobre la posibilidad de recarga artificial en la Cubeta de Santiuste (Segovia): España, Informe no publicado.

Pérez-Paricio, A., 2000, Integrated modelling of clogging of artificial recharge systems:Universidad Politécnica de Cataluña, Tesis Doctoral, $105 \mathrm{p}$.

Pettersson, B., Axen, B., 1980, Thermography. Testing of the thermal insulation and airtightness of buildings, en Steen, B., (ed.), Swedish Council for Building Research, Stockholm, $227 \mathrm{p}$.

Pierce, L., Running, S.,Riggs, G., 1990, Remote detection of canopy water stress in coniferous forests using the NS001 Thematic Mapper Simulator and thermal infrared multispectral scanner: Photommetric Engineering and Remote Sensing, 56, 579-586.
Ryan, J.N., Elimelech, M., 1996, Colloid mobilization and transport in groundwater. Colloids and Surfaces. A: Physicochemical and Engineering Aspects, 107, 1-56.

Shahraeeni, E., Or, D., 2010, Thermo-evaporative fluxes from heterogeneous porous surfaces resolved by infrared thermography, Water Resources Research, 46, 9, 160-178.

Van Beek, C., 1986, Clogging of discharge wells in the Netherlands II: Causes and prevention, International Symposium of biofouled aquifers: prevention and restoration, American Water Works Association, Denver, 42-56.

Manuscrito recibido: Junio 3, 2011.

Manuscrito corregido recibido: Octubre 15, 2012.

Manuscrito aceptado: Noviembre 16, 2012. 